\title{
Cardiolipin Profile Changes are Associated to the Early Synaptic Mitochondrial Dysfunction in Alzheimer's Disease
}

\author{
Vera F. Monteiro-Cardoso ${ }^{\mathrm{a}}$, M. Manuel Oliveira ${ }^{\mathrm{a}}$, Tânia Melo ${ }^{\mathrm{b}}$, Maria R.M. Domingues ${ }^{\mathrm{b}}$, \\ Paula I. Moreira ${ }^{\mathrm{c}, \mathrm{d}}$, Elisabete Ferreiro ${ }^{\mathrm{d}, \mathrm{e}}$, Francisco Peixoto ${ }^{\mathrm{f}}$ and Romeu A. Videira ${ }^{\mathrm{a}, *}$ \\ ${ }^{a}$ Chemistry Center - Vila Real $(C Q-V R)$, Chemistry Department, School of Life and Environmental Sciences, \\ University of Trás-os-Montes e Alto Douro, UTAD, Vila Real, Portugal \\ ${ }^{\mathrm{b}}$ Mass Spectrometry Center, UI-QOPNA, Chemistry Department, University of Aveiro, Aveiro, Portugal \\ ${ }^{\mathrm{c}}$ Laboratory of Physiology, Faculty of Medicine, University of Coimbra, Coimbra, Portugal \\ ${ }^{\mathrm{d}} \mathrm{CNC}-$ Center for Neuroscience and Cell Biology, University of Coimbra, Coimbra, Portugal \\ e Institute for Interdisciplinary Research (IIIUC), University of Coimbra, Coimbra, Portugal \\ ${ }^{\mathrm{f}}$ Centre for the Research and Technology of Agro-Environmental and Biological Sciences (CITAB), Department of \\ Biology and Environment, School of Life and Environmental Sciences, UTAD, Vila Real, Portugal
}

\begin{abstract}
Brain mitochondria are fundamental to maintaining healthy functional brains, and their dysfunction is involved in age-related neurodegenerative disorders such as Alzheimer's disease (AD). In this study, we conducted a research on how both non-synaptic and synaptic mitochondrial functions are compromised at an early stage of AD-like pathologies and their correlation with putative changes on membranes lipid profile, using 3 month-old nontransgenic and 3xTg-AD mice, a murine model of experimental AD. Bioenergetic dysfunction in 3xTg-AD brains is evidenced by a decrease of brain ATP levels resulting, essentially, from synaptic mitochondria functionality disruption as indicated by declined respiratory control ratio associated with a 50\% decreased complex I activity. Lipidomics studies revealed that synaptic bioenergetic deficit of 3xTg-AD brains is accompanied by alterations in the phospholipid composition of synaptic mitochondrial membranes, detected either in phospholipid class distribution or in the phospholipids molecular profile. Globally, diacyl- and lyso-phosphatidylcholine lipids increase while ethanolamine plasmalogens and cardiolipins content drops in relation to nontransgenic background. However, the main lipidomic mark of 3xTg-AD brains is that cardiolipin cluster-organized profile is lost in synaptic mitochondria due to a decline of the most representative molecular species. In contrast to synaptic mitochondria, results support the idea that nonsynaptic mitochondria function is preserved at the age of 3 months. Although the genetically construed 3xTg-AD mouse model does not represent the most prevalent form of $\mathrm{AD}$ in humans, the present study provides insights into the earliest biochemical events in AD brain, connecting specific lipidomic changes with synaptic bioenergetic deficit that may contribute to the progressive synapses loss and the neurodegenerative process that characterizes AD.
\end{abstract}

Keywords: Alzheimer's disease, brain bioenergetics, cardiolipin, mitochondrial lipidomics

\section{INTRODUCTION}

${ }^{*}$ Correspondence to: Romeu A. Videira, Chemistry Center - Vila Real (CQ-VR), Chemistry Department, School of Life and Environmental Sciences, University of Trás-os-Montes e Alto Douro, UTAD, P.O. Box 1013, 5001-801 Vila Real, Portugal. Tel.: +351 259350273; Fax: +351 259350 480; E-mail: rvideira@utad.pt.
Lipids are a structurally high diverse group of amphiphilic molecules with a key biological role in energy storage and demand, in the dynamic structure of biomembranes, and in several cell signaling pathways $[1,2]$. In multicellular organisms, the spatial 
and temporal regulation of lipidome reaches a high level of complexity, which includes a transversal (lipid asymmetry) and a lateral (lipid domains) dynamic membrane organization $[1,2]$. Therefore, the cornerstone of the highly complex eukaryotic organisms (as humans) is a continuous high energy flux required to the dynamic regulation (in time and space) of a vastly expanded repertoire of lipid species. Mitochondria, which supply more than $90 \%$ of the ATP used by animal cells, must be a key player in the homeostatic control of lipidome. Thus, it is not surprising that human diseases connected with aberrant lipid metabolism (e.g., Alzheimer's disease, AD) are also associated with mitochondrial dysfunction [3, 4].

$\mathrm{AD}$ is the most common neurodegenerative disorder predominantly characterized at the brain level by extracellular deposition of amyloid- $\beta$ (A $\beta$ ) peptide, intracellular neurofibrillary tangles containing hyperphosphorylated tau protein, and synaptic dysfunction [5]. Since Dr. Alois Alzheimer described this disorder over 100 years ago, a number of molecular mechanisms underlying altered biochemical pathways have been identified as potential causes of AD [6-9]. Abnormal enzymatic processing of amyloid- $\beta$ protein precursor $(\mathrm{A} \beta \mathrm{PP})$ raised the first hypothesis for $\mathrm{AD}$, the amyloid cascade hypothesis, which postulates that generation of $\mathrm{A} \beta$ fragments and the formation of senile plaques trigger $\mathrm{AD}$ pathology [9]. A $\beta P P$ is a transmembrane glycoprotein implicated in neural plasticity and synapse formation. The mechanism by which $A \beta P P$ is cleaved is not fully understood, but two pathways have been reported. Normally, A $\beta P P$ follows the constitutive nonamyloidogenic pathway via $\alpha$-secretase, releasing the neurotropic ectodomain (soluble $\mathrm{A} \beta \mathrm{PP}$ ) in the extracellular space; but it can also undergo an amyloidogenic process via BACE ( $\beta$-site cleaving enzyme), leading to $A \beta$ formation with consequent neurotoxic effects [10]. It is reported that A $\beta P P$ and $\alpha$-secretase are mainly located in lipid disordered domains (Ld or L $\alpha$ phase) while its proteolytic enzyme (BACE) resides in lipid ordered domains (Lo phase or rafts) [11]. Thus, the regulation of lateral compartmentalization of the membrane is essential to prevent the neurodegenerative process induced by $A \beta$. However, the soluble $A \beta$ levels are better correlated with dementia severity than amyloid deposits [12]. Soluble $A \beta$ itself can interact with membrane lipids, promoting changes in the dynamic organization of cell membranes, including mitochondrial membranes [13]. In fact, profound alterations on mitochondrial enzyme activity were associated with $\mathrm{AD}$ and mitochondrial dysfunction was also proposed as the primary event leading to $\mathrm{AD}$ pathology $[14,15]$. Brain mitochondrial dysfunction, characterized by reduced ATP synthesis and enhanced reactive oxygen species (ROS) generation $[16,17]$, may underlie oxidative stress, the loss of cellular $\mathrm{Ca}^{2+}$ homeostasis and the disruption of the functional membrane structure, triggering both $\mathrm{A} \beta$ and tau pathologies.

Mitochondria functional integrity is highly dependent on phospholipid composition, mainly cardiolipin (CL) content and diversity [18-20]. CL, a unique anionic tetra-acyl phospholipid class in mammalian cells, is fundamental to the functional membrane assembly of redox complexes of the respiratory system and phosphorylation apparatus, regulating mitochondrial bioenergetics [21,22]. In this context, we aimed to evaluate the bioenergetic alterations and the mitochondrial membrane lipid profile at an early stage of $\mathrm{AD}$ in order to better understand how the putative mitochondrial phospholipid profile changes are reflected in brain mitochondrial bioenergetics, in brain ATP levels and brain redox state usually associated with AD pathology.

\section{MATERIAL AND METHODS}

\section{Animal care}

All animal experiments were conducted according with the National (DL 129/92; DL 197/96; P 1131/97) and European Convention for the Protection of Animals used for Experimental and Other Scientific Proposes and related European Legislation (2010/63/EU). Male nontransgenic (nonTg; C57BL6/129S) and triple transgenic (3xTg-AD) mice for $\mathrm{AD}$ were used, since they express three major genes associated with familial AD, namely APPswe, PS1M146V, and tauP301L, and develop the pathological hallmarks of disease in an age-dependent manner $[23,24]$. Thus, $A \beta$ and tau pathologies are detected at 6 and 12 months of age, respectively. Animals were obtained from Center for Neuroscience and Cell Biology (CNC) Animal Facility, University of Coimbra and maintained at veterinary hospital of the University of Trás-os-Montes e Alto Douro and were housed in polycarbonate cages on a $12 \mathrm{~h}$ light/dark cycles. Room temperature was maintained at $24 \pm 2{ }^{\circ} \mathrm{C}$ with relative humidity $55 \pm 5 \%$. Food and water were provided ad libitum. Although the experiments performed in the present work were carried out in 3-month old presymptomatic male mice, the neuropathological hallmarks were assessed in 14-month old male nonTg and 3xTg-AD. The extracellular $A \beta$ deposits and intracellular deposits of hyperphosphorylated tau protein were detected by 


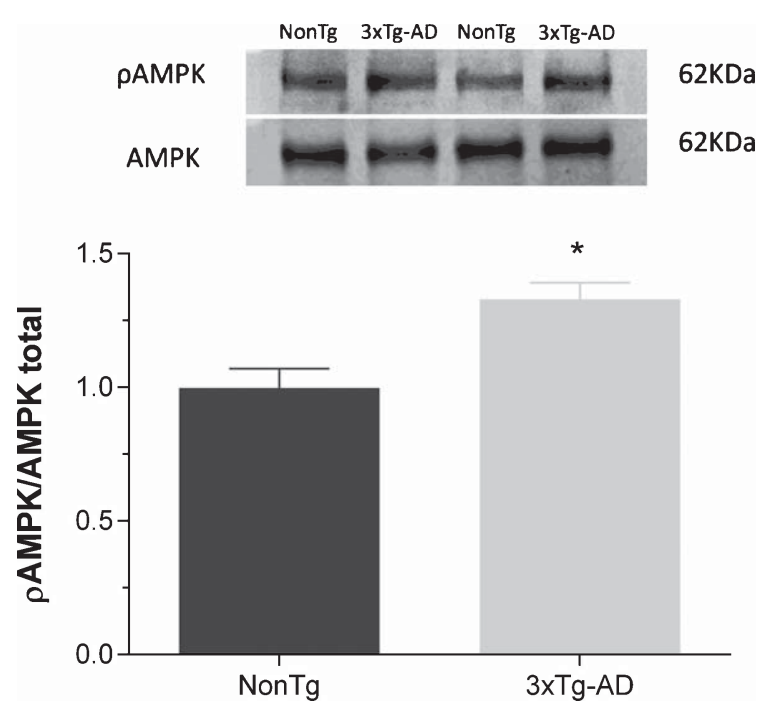

Fig. 1. Phosphorylated AMPK (pAMPK) to AMPK total ratio. Representative western blots of pAMPK and AMPK total (upper panel). Bar graphs show pAMPK/AMPK total ratio, determined by western blot analysis, in brain mitochondria-free extracts obtained from 3 months-old nonTg and 3xTg-AD mice. Error bars represent standard deviation for $n \geq 3$ independent experiments using 3 animals in each one. *Significantly different from nonTg group, with $p \leq 0.05$.

immunohistochemistry using 6E10 and AT8 antibodies, respectively (Supplementary Figure 1).

\section{Determination of brain ATP, ADP, and AMP levels}

Adenine nucleotides (ATP, ADP, and AMP) were extracted from nonTg and $3 \times \mathrm{Tg}-\mathrm{AD}$ brains using a modified tissue extraction protocol as described elsewhere [25]. ATP, ADP, and AMP were quantified by high performance liquid chromatography (HPLC) (UltiMate 3000, Dionex) using standard curves obtained with the chromatogram peak areas corresponding to different concentrations of each adenine nucleotides. The results were expressed as $\mu \mathrm{mol} / \mathrm{g}$ wet brain.

Determination of enzymatic and non-enzymatic antioxidant defenses in brain mitochondria-free cytosolic fraction

Brain enzymatic (superoxide dismutase, SOD; catalase, CAT) and non-enzymatic (glutathione, GSH; glutathione disulfide, GSSG) antioxidant defenses as well ROS generation were measured in mitochondriafree cytosolic fraction from nonTg and $3 \times \mathrm{Tg}-\mathrm{AD}$ mice brains. Brains were homogenized in ice-could buffer (160 mM sucrose, $10 \mathrm{mM}$ Tris-HCl, $\mathrm{pH} 7.4)$ $(1: 10, \mathrm{p} / \mathrm{v})$ using a glass-Teflon Potter Elvjhem. Brain mitochondria-free cytosolic fractions were obtained after centrifugation at $16000 \mathrm{~g}$ for $20 \mathrm{~min}$ at $4{ }^{\circ} \mathrm{C}$ (Sigma 2K-16). The final concentration of protein was determined by the Biuret method [26].

Copper-zinc SOD (CuZn-SOD) activity was evaluated using $0.2 \mathrm{mg}$ of protein into phosphate buffer (50 $\mathrm{mM} \mathrm{KH}_{2} \mathrm{PO}_{4}, 1$ mM EDTA, pH 7.4) supplemented with $0.1 \mathrm{mM}$ nitro blue tetrazolium (NBT) and $0.1 \mathrm{mM}$ hipoxantine [27]. Absorbance was measure in a Cary 50 UV-Vis spectrophotometer (Agilent Technologies, Santa Clara, CA, USA) at $560 \mathrm{~nm}$ after $0.023 \mathrm{U} \mathrm{mol}^{-1}$ xanthine oxidase addition. The values were expressed as $\mathrm{U} / \mathrm{min} / \mathrm{mg}$ protein in which $\mathrm{U}$ is define as the enzyme activity that inhibited the reduction of NBT to blue formazan by $50 \%$.

CAT activity was determined polarographically following the oxygen production using a Clark-type oxygen electrode (Hansatech, Norfolk, UK) resulting from $\mathrm{H}_{2} \mathrm{O}_{2}$ decomposition [28]. The reaction was conducted in $1 \mathrm{~mL}$ of $50 \mathrm{mM}$ sodium phosphate buffer $(\mathrm{pH}$ 7.0) and initiated by adding $1 \mathrm{M} \mathrm{H}_{2} \mathrm{O}_{2}$. CAT activity was expressed in terms of nmol $\mathrm{O}_{2}$ produced per minute per milligram protein.

GSH and GSSG levels were determined by spectrofluorimetric assay, using a Varian Eclipse fluorescence spectrophotometer (Agilent Technologies, Santa Clara, CA, USA) setting excitation at $350 \mathrm{~nm}$ and emission at $420 \mathrm{~nm}$ [29]. To determine GSH content, samples $(0.5 \mathrm{mg}$ of protein) were incubated at room temperature in $2.5 \mathrm{~mL}$ of phosphate buffer (100 mM potassium phosphate, $5 \mathrm{mM}$ EDTA, pH 8.0) supplemented with $200 \mu \mathrm{g}$ fluorochrome orthophthalaldehyde (OPT) for $15 \mathrm{~min}$. To determinate GSSG content, samples $(0.5 \mathrm{mg}$ of protein) were first incubated at $22^{\circ} \mathrm{C}$ with $12 \mathrm{mM} \mathrm{N}$-ethylmaleimide (NEM) for $45 \mathrm{~min}$. After that $1.66 \mathrm{~mL}$ of $0.1 \mathrm{M} \mathrm{NaOH}$ and $0.7 \mathrm{~mL}$ of phosphate buffer supplemented with $200 \mu \mathrm{g}$ OPT were added to the reaction followed by $15 \mathrm{~min}$ incubation at $22^{\circ} \mathrm{C}$. Concentrations were calculated using standard curves prepared with different concentrations of GSH and GSSG which underwent the same sample treatment. The results were expressed as GSH/GSSG ratio.

ROS production in brain mitochondria-free cytosolic fractions was estimated using the fluorescent probe $2^{\prime}, 7^{\prime}$-dichlorofluorescein diacetate (DCFH-DA) [30]. Samples $(0.1 \mathrm{mg}$ of protein) were incubated with DCFH-DA $(5 \mu \mathrm{M})$ at $37^{\circ} \mathrm{C}$ for $45 \mathrm{~min}$. Fluorescence intensity of $2^{\prime}, 7^{\prime}$-dichlorofluorescein (DCF) was measured in a Varian Eclipse fluorescence spectrophotometer (Agilent Technologies, Santa Clara, CA, USA) at $480 \mathrm{~nm}$ excitation and $535 \mathrm{~nm}$ and emission 
wavelengths. ROS content was determined using a calibration curve obtained with DCF standards. Results were expressed as nmol DCF per milligram of protein.

\section{Western blots analysis of $5^{\prime}$ adenosine} monophosphate-activated protein kinase (AMPK)

AMPK total and phosphorylated AMPK levels in nonTg and $3 \times \mathrm{Tg}-\mathrm{AD}$ mice brains were evaluated by western blots analysis [31]. Western blots were performed in the mitochondria-free cytosolic fractions obtained as described above and supplemented with phosphatase inhibitors cocktail (Roche). The samples were resolved by electrophoresis in $10 \%$ SDS-polyacrylamide gels and transferred to polyvinylidene difluoride (PVDF) membranes. The blots were subsequently incubated with specific primary antibodies [p-AMPK alpha (T172) Antibody from Cell Signaling catalog \#2451 (1:1.000); AMPK alpha Antibody from Cell Signaling catalog \#2532] overnight at $4{ }^{\circ} \mathrm{C}$. After quick washes with TBS containing $0.1 \%$ Tween (TBS-T), the membranes were incubated with secondary antibodies for $2 \mathrm{~h}$ at room temperature and again washed with TBS-T. Specific bands of immunoreactive proteins were visualized in a VersaDoc Imaging System (Bio-Rad) after 5-min incubation with enhanced chemifluorescence. The density of protein bands was calculated using the Quantity One Program (Bio-Rad). Results were expressed as the ratio of phosphorylated AMPK to AMPK total.

\section{Determination of acetylcholinesterase (AChE) activity in brain mitochondria-free cytosolic fraction}

AChE activity was evaluated in brain mitochondriafree cytosolic fraction, as previously described [19]. Briefly, $2 \mathrm{~mL}$ of phosphate buffer $\left(0.1 \mathrm{M} \mathrm{KH}_{2} \mathrm{PO}_{4}\right.$, $\mathrm{pH}$ 7.4) supplemented with $10 \mu \mathrm{L}$ of brain homogenate, $0.1 \mathrm{mM}$ ethopropazine and $10 \mu \mathrm{L}$ of Ellman's reagent (0.15 mM 5,5-dithio-bis-2-nitrobenzoic acid (DTNB) in $0.1 \mathrm{M}$ phosphate buffer, $\mathrm{pH} 7.4$ ) were incubated at $25^{\circ} \mathrm{C}$ for $2 \mathrm{~min}$. The reaction was initiated by adding substrate acetylthiocholine and the catalytic activity was measured by following the increase in absorbance at $412 \mathrm{~nm}$ for $3 \mathrm{~min}$, using a Cary $50 \mathrm{UV}$-Vis spectrophotometer (Agilent Technologies, Santa Clara, CA, USA). AChE activity was evaluated as a function of substrate concentration, using seven concentrations of acetylthiocholine iodide, from 16 to $2000 \mu \mathrm{M}$, to determine the Michaelis-Menten kinetic parameters $\mathrm{Km}$ (Michaelis constant) and $\mathrm{V}_{\max }$ (maximal velocity).

\section{Brain mitochondria isolation and mitochondrial respiration}

Non-synaptic and synaptic brain mitochondria from both nonTg and 3xTg-AD mice were isolated combining differential centrifugations with Ficoll (Sigma-Aldrich, Madrid, Spain) and sucrose density gradients centrifugations, as previously described [32]. First, non-synaptic mitochondria and synaptosomes fractions were obtained with Ficoll discontinuous gradient. Synaptic mitochondria were obtained after synaptosomes lysate in a hypotonic buffer. Finally, both synaptic and non-synaptic mitochondria were purified using a sucrose discontinuous gradient. This procedure yield highly enriched synaptic and nonsynaptic mitochondria populations free from myelin, synaptosomal membrane, cytoskeleton, nuclear membrane, Golgi membrane and microsomal membrane, as previously shown by western blots analysis of typical protein marks of those subcellular compartments [32]. The final concentration of synaptic and non-synaptic mitochondrial protein was determined by the Biuret method [26].

Oxygen consumption of fresh brain mitochondria was monitored polarographically with a Clark-type oxygen electrode (Hansatech, Norfolk, UK) at $30^{\circ} \mathrm{C}$. $1 \mathrm{mg}$ of mitochondrial protein was added to the reaction medium $(130 \mathrm{mM}$ sucrose, $50 \mathrm{mM} \mathrm{KCl}, 5 \mathrm{mM}$ $\mathrm{MgCl}_{2}, 5 \mathrm{mM} \mathrm{KH}_{2} \mathrm{PO}_{4}$, and $5 \mathrm{mM}$ HEPES at $\mathrm{pH}$ 7.2) and mitochondria were energized with $5 \mathrm{mM}$ pyruvate $/ 5 \mathrm{mM}$ malate. State 3 was started by adding ADP (100 nmol/mg of protein). State 4 respiration corresponds to resting oxygen consumption rate after ADP phosphorylation. Oxygen consumption was expressed as nmol $\mathrm{O}_{2} / \mathrm{min} . / \mathrm{mg}$ of protein. Respiratory control ratio (RCR) is defined as the ratio of state 3 to state 4 respiration rates.

\section{Determination of mitochondrial enzymes activity}

Before mitochondrial enzymes activity evaluation, non-synaptic and synaptic mitochondria were submitted to several cycles of freezing/thawing in order to allow substrate access to the inner mitochondrial membrane. Mitochondrial enzymatic assays were conducted at $30^{\circ} \mathrm{C}$. Complexes I, II, and IV and $\mathrm{F}_{\mathrm{o}} \mathrm{F}_{1}$ ATPase activities were evaluated and normalized with citrate synthase (CS) activity as previously described [33].

CS was determined spectrophotometrically monitoring the reduction of DTNB. The reaction mixture consisted of $200 \mathrm{mM}$ Tris- $\mathrm{HCl}$ buffer ( $\mathrm{pH} \mathrm{8.0),} 0.02 \%$ 
Triton X-100, $10 \mu \mathrm{M}$ DTNB, $1 \mathrm{mM}$ oxaloacetate, and $0.2 \mathrm{mg}$ of mitochondrial protein. The reaction was initiated by adding $0.37 \mathrm{mM}$ acetyl-CoA and monitored at $412 \mathrm{~nm}$ in a Cary $50 \mathrm{UV}$-Vis spectrophotometer (Agilent Technologies, Santa Clara, CA, USA). The specific activity of CS was calculated by DTNB (extinction coefficient $13600 \mathrm{M}^{-1} \mathrm{~cm}^{-1}$ ) reduction rate, determined in the linear range of the plot and expressed as $\mathrm{nmol} / \mathrm{min} / \mathrm{mg}$ protein.

Complex I (NADH-ubiquinone oxidoredutase) was evaluated spectrofluorimetrically following reduced nicotinamide-adenine dinucleotide (NADH) oxidation. NADH $(50 \mu \mathrm{M})$ fluorescence intensity was evaluated before and after adding $162.5 \mu \mathrm{M}$ decylubiquinone to the reaction medium $\left(25 \mathrm{mM} \mathrm{KH}_{2} \mathrm{PO}_{4}\right.$, $10 \mathrm{mM} \mathrm{MgCl}_{2} ; \mathrm{pH} 7.4$ ) supplemented with $1 \mathrm{mM} \mathrm{KCN}$ and $0.3 \mathrm{mg}$ of mitochondrial suspension. The reaction was followed in a Varian Eclipse fluorescence spectrophotometer (Agilent Technologies, Santa Clara, CA, USA) at $450 \mathrm{~nm}$, setting excitation at $366 \mathrm{~nm}$. Enzyme activity was determined by the difference between the slopes before and after $3.0 \mu \mathrm{M}$ rotenone (specific complex I inhibitor) addition. This value was expressed in arbitrary units/min/mg.

Complex II (Succinate Dehydrogenase) activity was assessed monitoring 2,6-dichlorophenolindo-phenol (DCIP) reduction at $600 \mathrm{~nm}$ in a $25 \mathrm{mM}$ potassium phosphate buffer $\mathrm{pH} 7.4$ containing $0.2 \mathrm{mg}$ of mitochondrial protein, $2 \mathrm{mM} \mathrm{KCN}, 6.5 \mu \mathrm{M}$ rotenone, $6.5 \mu \mathrm{M}$ antimycin $A, 0.05 \mathrm{mM}$ DCIP, and $0.1 \mathrm{mM}$ decylubiquinone. The reaction was initiated by adding $20 \mathrm{mM}$ succinate and stopped $5 \mathrm{~min}$ later by adding $0.5 \mathrm{mM}$ oxaloacete (complex II inhibitor). The extinction coefficient used for DCIP was $21000 \mathrm{M}^{-1} \mathrm{~cm}^{-1}$.

Complex IV (cytochrome c oxidase) activity was evaluated by the oxygen consumption in a Clarktype oxygen electrode (Hansatech, Norfolk, UK) associated to cytochrome $c$ oxidation promoted by $5 \mathrm{mM}$ ascorbate $/ 2.5 \mathrm{mM} N, N, N^{\prime}, N^{\prime}$-tetramethyl1,4-benzenediamine dihydrochloride (TMPD). The reaction was initiated by addition of ascorbate/TMPD into standard buffer $(130 \mathrm{mM}$ sucrose, $50 \mathrm{mM} \mathrm{KCl}$, $5 \mathrm{mM} \mathrm{MgCl}_{2}, 5 \mathrm{mM} \mathrm{KH} \mathrm{PO}_{4}$, and $5 \mathrm{mM}$ HEPES; $\mathrm{pH}$ 7.2) supplemented with $0.2 \mathrm{mg}$ mitochondrial suspension, $3 \mu \mathrm{M}$ rotenone, $0.1 \mu \mathrm{M}$ antimycin $\mathrm{A}$ (inhibitor of complex III) and $15 \mu \mathrm{M}$ cytochrome $c$. KCN ( $2 \mathrm{mM}$; specific inhibitor of complex IV) was used to stop the reaction. Complex IV activity was expressed as nmol $\mathrm{O}_{2} / \mathrm{min} / \mathrm{mg}$ protein.

$\mathrm{F}_{\mathrm{o}} \mathrm{F}_{1}$-ATPase activity was determined using a Crison $\mathrm{pH}$ evaluation system (Barcelona, Spain) connected to a Kipp and Zonen recorder (Omni Instru- ments, Dundee, UK), as previously described [34]. Assay buffer $(130 \mathrm{mM}$ sucrose, $60 \mathrm{mM} \mathrm{KCl}, 0.5 \mathrm{mM}$ Hepes, and $2.5 \mathrm{mM} \mathrm{MgCl}_{2} ; \mathrm{pH} 7.0$ ) was supplemented with $3 \mu \mathrm{M}$ rotenone and $0.2 \mathrm{mg}$ of mitochondrial protein. The reaction was initiated by adding $2 \mathrm{mM}$ ATP-Mg and stopped by adding $1 \mu \mathrm{g}$ oligomycin, since ATP hydrolysis results in transmembrane proton translocation. At the end of each reaction assay system calibration was performed using a standard $\mathrm{HCl}$ solution. $\mathrm{F}_{\mathrm{o}} \mathrm{F}_{1}$-ATPase activity was expressed as nmol $\mathrm{H}^{+} /$min./mg protein.

\section{Lipid extraction and phospholipid quantification}

Phospholipids extraction from non-synaptic and synaptic mitochondria was performed using a double extraction procedure with a solvent combination of methanol/chloroform/water at final proportions of 2:1:0.8 (v/v/v) [33]. A volume of mitochondrial suspension corresponding to $5 \mathrm{mg}$ of protein was reconstituted in $0.8 \mathrm{~mL}$ aqueous buffer. Internal standards were added based on mitochondrial protein concentration (per mg of protein): $0.7 \mu \mathrm{g}$ phosphotidylcholine, PC (14:0/14:0); $0.2 \mu \mathrm{g}$ sphingomyelin, SM (d18:1/12:0); $0.2 \mu \mathrm{g}$ lyso-phosphotidylcholine, LPC (14:0/0:0), $0.3 \mu \mathrm{g}$ phosphatidylinositol, PI (16:0/16:0); $0.45 \mu \mathrm{g}$ phosphatidylethanolamine, PE (14:0/14:0); $0.3 \mu \mathrm{g}$ phosphatidic acid, PA (14:0/14:0); $0.35 \mu \mathrm{g}$ phosphatidylserine, PS (14:0/14:0); $0.34 \mu \mathrm{g}$ cardiolipins, CL (14:0/14:0/14:0/14:0); and $0.3 \mu \mathrm{g}$ phosphotidylglycerol, PG (14:0/14:0). Mitochondrial samples with internal standards were mixed with $2 \mathrm{~mL}$ methanol for $5 \mathrm{~min}$ and then $1 \mathrm{~mL}$ chloroform was added. The mixture was blended for more $5 \mathrm{~min}$ and then centrifuged at $2000 \mathrm{~g}$ (Sigma 2-16K) for $5 \mathrm{~min}$ at $4{ }^{\circ} \mathrm{C}$. Supernatant was collected and an additional volume of $1 \mathrm{~mL}$ chloroform and $2 \mathrm{~mL} \mathrm{H}_{2} \mathrm{O}$ were added followed by $5 \mathrm{~min}$ mixing. Finally, samples were centrifuged at $2000 \mathrm{~g}$ for $5 \mathrm{~min}$ at $4^{\circ} \mathrm{C}$, in order to obtain a two-phase system: an aqueous top phase and an organic bottom phase from which lipids were collected. The palette obtained in the first centrifugation was used to perform lipid re-extraction.

In order to quantify membrane phospholipids content, phosphorus assay was performed according to the method outlined by Bartlett and Lewis [35]. Briefly, $0.65 \mathrm{~mL}$ of concentrate perchloric acid $(70 \%, \mathrm{w} / \mathrm{v})$ were added to lipid samples $(50-100 \mu \mathrm{L})$ previously dried with nitrogen stream and then incubated at $180^{\circ} \mathrm{C}$ for $2 \mathrm{~h} .3 .3 \mathrm{~mL}$ of $\mathrm{H}_{2} \mathrm{O}, 0.5 \mathrm{~mL}$ of $1 \%(\mathrm{w} / \mathrm{v})$ ammonium molybdate, and $4 \%(\mathrm{w} / \mathrm{v})$ ascorbic acid were added to all samples, followed by incubation at $100^{\circ} \mathrm{C}$ 
for $10 \mathrm{~min}$ in a water bath. Standards from 0 to 250 nmol phosphate underwent the same sample treatment. Standards and samples absorbance was measured at $800 \mathrm{~nm}$ in a Varian Cary 50 spectrophotometer. After quantification, extracted lipids were split per glass ampoules in pools of $322.5 \mathrm{nmol}(10 \mu \mathrm{g})$ phosphorous. Samples were dried under nitrogen atmosphere and stored at $-20^{\circ} \mathrm{C}$ in sealed glass ampoules. Before

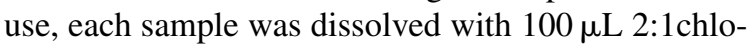
roform/methanol (v/v) mixture.

\section{Separation and quantification of phospholipid classes by high pressure liquid chromatography - mass spectrometry (HPLC-MS)}

Phospholipid classes were solved on an HPLC system (Waters Alliance 2690) coupled to an electrospray linear ion trap mass spectrometer (ThermoFinnigan, San Jose, CA, USA) [36]. The mobile phase A consisted of $10 \%$ water and $55 \%$ acetonitrile with $35 \%$ (v/v) methanol. The mobile phase B consisted of acetonitrile $60 \%$, methanol $40 \%$ with $10 \mathrm{mM}$ amonium acetate. Total lipid extract was diluted in the mobile phase A (1:1, v/v) and introduced into an Ascentis Si HPLC Pore column $(15 \mathrm{~cm} \times 1.0 \mathrm{~mm}, 3 \mu \mathrm{m})$ (SigmaAldrich). Solvents gradient started with $0 \%$ of phase A followed by a linear increase to $100 \%$ of phase A during $20 \mathrm{~min}$, and held isocratically for $35 \mathrm{~min}$, returning, to the initial conditions in $5 \mathrm{~min}$. The flow rate through the column was $16 \mu \mathrm{L} / \mathrm{min}$. obtained using a pre-column split (Acurate, HPLC Packings, USA). Mass electrospray analysis was done using the following parameters: source voltage, $5 \mathrm{kV}$, positive mode, $4.7 \mathrm{kV}$, negative mode, source temperature, $275^{\circ} \mathrm{C}$, sheath gas flow, $8 \mathrm{U}$, source current, 100 ua, capillary voltage, $10 \mathrm{~V}$, positive mode, $-43 \mathrm{~V}$ negative mode. An isolation with of $0.5 \mathrm{Da}$ was used with a $30-\mathrm{ms}$ activation time for MS/MS experiments. Data acquisition and treatment of results were carried out with an Xcalibur data system (V2.0, ThermoFinnigan, San Jose, CA, USA). Quantitation of individual molecular phospholipid species were calculated by determining the ratio of the peak area of each molecular species to the corresponding internal standard.

Separation of cardiolipin by thin layer chromatography (TLC) and its analysis by electrospray mass spectrometry (ESI-MS)

Phospholipid classes from the total lipid extracts were separated by TLC using silica gel plates [19]. Prior to separation, plates were washed with chloroform/methanol $(1: 1, \mathrm{v} / \mathrm{v})$ and treated with $2.3 \%(\mathrm{w} / \mathrm{v})$ boric acid in ethanol. The plates with spots containing between 20 and $30 \mu \mathrm{g}$ of phosphorous were developed in solvent mixture chloroform/ethanol/water/triethylamine (35:30:7:35, $\mathrm{v} / \mathrm{v} / \mathrm{v} / \mathrm{v})$. Lipid spots on TLC plates were detected with a UV lamp $(\mathrm{k}=254 \mathrm{~nm})$ after primuline $(50 \mu \mathrm{g} / 100 \mathrm{~mL}$ in acetone/water, 80:20; v/v) exposure. CL was identified by using a CL standard and correspondent TLC spot was scraped off the plates to lipid extraction and further electrospray mass spectrometry analysis.

CL lipid extracts were directly analyzed by ESI-MS in negative mode in an electrospray linear ion trap mass spectrometer (ThermoFinnigan, San Jose, CA, USA), following the conditions indicated above for lipid analysis in negative ion mode. CL MS analyses were performed in three independent samples.

\section{Statistical analysis}

All the data presented in this study correspond to the mean value of $n$ independent experiments $\pm S D$, with $n \geq 3$. In each independent experiment at least three animals were used. Comparison of two data sets was performed with one-way ANOVA test. Data sets were considered statistically different when $p<0.05$.

\section{RESULTS}

\section{Non-synaptic and synaptic mitochondrial bioenergetics state}

Decline of glucose metabolism has been identified as a characteristic phenotype in both AD patients and animal models for $\mathrm{AD}[37,38]$. Therefore, the overall brain adenine nucleotides levels and non-synaptic and synaptic mitochondria activities were evaluated using animals in presymptomatic condition (3 months of age) in order to assess whether brain bioenergetics is compromise at an early stage of the disease. Although the global levels of adenine nucleotides is similar in both groups, significant differences were detected in ATP (nonTg 2.030 $\pm 0.134,3 x \mathrm{Tg}-\mathrm{AD} 1.620 \pm 0.102$ ) and AMP (nonTg $0.275 \pm 0.024,3 \times T g-A D 0.385 \pm 0.042$ ) levels, leading to an increase of AMP/ATP ratio in 3xTg-AD brains (Table 1). This increased AMP/ATP ratio may has functional consequences, since a parallel increase of phosphorylated AMPK/AMPK total ratio was detected (Fig. 1). Brain energy charge and ATP/ADP ratio were also determined and, despite the absence of significant differences, a slight decrease in these bioenergetic indicators was observed in $3 \mathrm{xTg}$ - 
Table 1

Brain adenine nucleotide levels in nonTg and 3xTg-AD mice and respiratory parameters of non-synaptic and synaptic mitochondria from nonTg and 3xTg-AD mice, using pyruvate/malate as substrate

\begin{tabular}{|c|c|c|c|c|}
\hline & \multicolumn{2}{|c|}{ NonTg } & \multicolumn{2}{|c|}{$3 x T g-A D$} \\
\hline$\overline{\mathrm{ATP}}(\mu \mathrm{mol} / \mathrm{g}$ wet brain $)$ & \multicolumn{2}{|c|}{$2.030 \pm 0.134$} & \multicolumn{2}{|c|}{$1.620 \pm 0.102^{*}$} \\
\hline ADP ( $\mu \mathrm{mol} / \mathrm{g}$ wet brain $)$ & \multicolumn{2}{|c|}{$0.878 \pm 0.078$} & \multicolumn{2}{|c|}{$0.823 \pm 0.097$} \\
\hline AMP ( $\mu \mathrm{mol} / \mathrm{g}$ wet brain $)$ & \multicolumn{2}{|c|}{$0.275 \pm 0.024$} & \multicolumn{2}{|c|}{$0.385 \pm 0.042^{*}$} \\
\hline $\mathrm{ATP}+\mathrm{ADP}+\mathrm{AMP}(\mu \mathrm{mol} / \mathrm{g}$ of wet brain $)$ & \multicolumn{2}{|c|}{$3.183 \pm 0.157$} & \multicolumn{2}{|c|}{$2.828 \pm 0.146$} \\
\hline ATP/ADP & \multicolumn{2}{|c|}{$2.312 \pm 0.255$} & \multicolumn{2}{|c|}{$1.968 \pm 0.263$} \\
\hline AMP/ATP & \multicolumn{2}{|c|}{$0.135 \pm 0.015$} & \multicolumn{2}{|c|}{$0.237 \pm 0.029 *$} \\
\hline \multirow[t]{3}{*}{ Brain energy charge } & \multicolumn{2}{|c|}{$0.776 \pm 0.066$} & \multicolumn{2}{|c|}{$0.718 \pm 0.056$} \\
\hline & \multicolumn{2}{|c|}{ Non-synaptic mitochondria } & \multicolumn{2}{|c|}{ Synaptic mitochondria } \\
\hline & NonTg & $3 \times T g-A D$ & NonTg & $3 \times T g-A D$ \\
\hline State 3 & $16.59 \pm 2.66$ & $18.59 \pm 3.81$ & $26.82 \pm 3.88$ & $13.70 \pm 2.56^{*}$ \\
\hline State 4 & $5.02 \pm 0.91$ & $5.48 \pm 0.34$ & $6.91 \pm 1.61$ & $8.60 \pm 0.89$ \\
\hline $\mathrm{RCR}$ & $3.30 \pm 0.24$ & $3.39 \pm 0.27$ & $3.88 \pm 0.28$ & $1.59 \pm 0.26^{*}$ \\
\hline
\end{tabular}

Results are expressed as mean \pm std of three independent experiments. *Significantly different from nonTg, with $p<0.05$.

AD brains (Table 1). These results indicate specific alterations in $\mathrm{AD}$ brain, considering all brain areas. However, brain is a spatial and cellular regionalized metabolic organ and AD pathology exhibits a specific spatial brain progression [39]. Thus, the bioenergetics changes that were detected may not be the result of brain random effects, but rather reflect significant alterations in brain regions preferentially affected by the disease. On the other hand, cellular metabolic regionalization emerges as a consequence of several brain cell types and the existence of two brain mitochondria populations. Brain mitochondria fall into non-synaptic (in neuronal and glial cell bodies) and synaptic (in synaptic bottom of neurons) which differ in both structural and functional features, such as bioenergetic activity and mitochondrial membrane lipid composition [32]. In this view, non-synaptic and synaptic brain mitochondria were isolated and purified in order to discriminate their contribution to the bioenergetic deficit detected in $3 \times T g-A D$ mice. The purity degree of both nonsynaptic and synaptic mitochondrial preparations was evidenced by a huge increase in citrate synthase activity (mitochondrial mark) of about $1800 \%$ in relation to brain homogenates. Additionally, cerebrosides and AChE activity (typical marks of plasma membrane, including myelin) were not detected and urate oxidase (a peroxisome mark) showed only residual activity in mitochondrial preparations (Supplementary Table 1). The general bioenergetic function of brain mitochondria was evaluated in both mitochondrial populations, considering the respiratory control rate and the individual activities of bioenergetic enzymatic complexes.

Mitochondrial respiration was activated by addition of pyruvate/malate and ADP to determine ADPstimulated respiration rate (state 3 ), whereas state 4 respiration rate was assessed after total ADP phosphorylation. Oxygen consumption rate in states 3 and 4 and the corresponding RCR are indicated in Table 1. In $3 \times \mathrm{Tg}$-AD group, only the synaptic brain mitochondria population exhibits lower RCR (nonTg $3.88 \pm 0.28$, $3 \times T g-A D ~ 1.59 \pm 0.26$ ), mainly resulting from a significant decrease in state 3 respiration. Since EGTA-free isolation buffer containing $1 \mathrm{mM}$ EDTA preserves the bioenergetic functionality of brain mitochondria [40], differences between non-synaptic and synaptic mitochondria or between nonTg and 3xTg-AD mice should not result from mitochondrial calcium overload during isolation procedures. Figure 2 displays CS normalized complex I, complex II, complex IV, and $\mathrm{F}_{\mathrm{o}} \mathrm{F}_{1}$-ATPase activities of non-synaptic and synaptic brain mitochondria, while their activities as well as citrate synthase activity, expressed per mg of protein, are shown in Supplementary Table 2.

The activity of the mitochondrial inner membraneconnected enzymes was normalized by CS activity, tightly correlated with morphometric data [41], in order to discern between mitochondrial dysfunction and simple differences in the mitochondria content of the preparations used to assess the enzyme activities. Complex I activity of 3xTg-AD synaptic mitochondria is shown to be significantly lower compared to complex I activity of nonTg synaptic mitochondria (nonTg $1.17 \pm 0.30,3 x T g-A D 0.61 \pm 0.05)$. Likewise, complex IV of non-synaptic and synaptic mitochondria and complex II of non-synaptic mitochondria isolated from 3xTg-AD animals exhibit lower activity than their age-matched controls. However, at this age (3 months old) these differences are of no statistical significance. Additionally, it is shown that $3 \mathrm{xTg}$-AD non-synaptic and synaptic mitochondria retain $\mathrm{F}_{\mathrm{o}} \mathrm{F}_{1}$-ATPase 

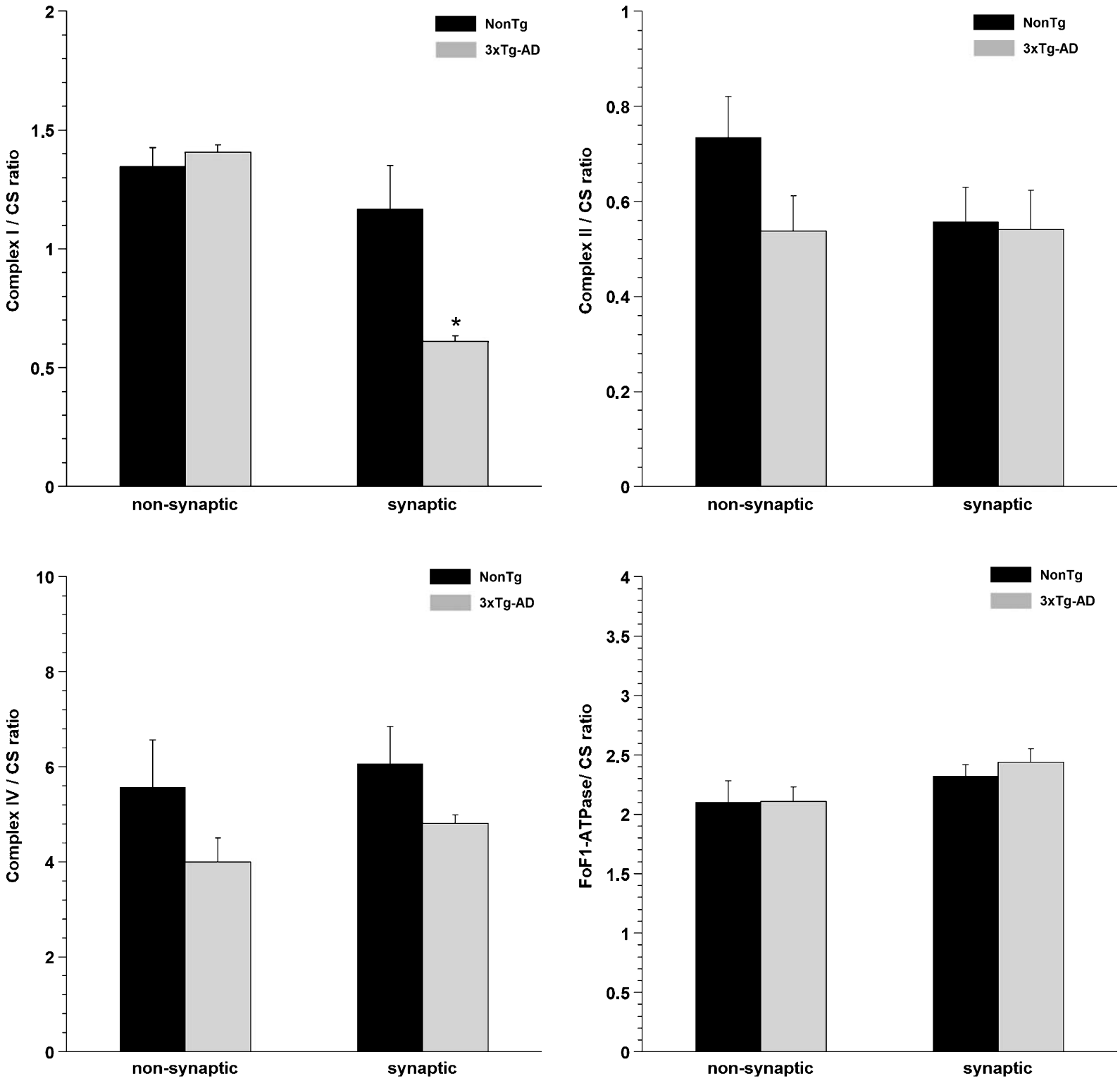

Fig. 2. Mitochondrial complexes I, II, and IV and $\mathrm{F}_{0} \mathrm{~F}_{1}$ ATPase activities normalized by CS activity. Black and grey bars represent 3 month-old nonTg and 3xTg-AD mice, respectively. Error bars represent standard deviation for $n \geq 3$ independent experiments using 3 animals in each one. Non-synaptic CS activity was $72.12 \pm 2.58$ and $92.81 \pm 1.82$ for nonTg and $3 x T g-A D$, respectively. Synaptic CS activity was $74.71 \pm 7.29$ and $74.68 \pm 2.54$ for nonTg and $3 x T g-A D$, respectively. *Significantly different from nonTg group, with $p \leq 0.05$.

activity, since their ability to couple ATP hydrolysis, associated to transmembrane proton translocation, is similar to that detected in nonTg non-synaptic and synaptic mitochondria, respectively (Fig. 2). Differences between nonTg and 3xTg-AD mice, however, cannot be attributed to technical variability ensuing from isolation effects putatively associated with the number of independent assays, since studies on bioenergetics using 6 to 12 month old animals revealed that synaptic mitochondrial deficits detected at the age of 3 months are exacerbated with aging and extended to non-synaptic brain mitochondria [42].

Taken together, these data indicate that synaptic mitochondria dysfunction is mainly associated with a decay in complex I activity that precedes non-synaptic mitochondrial dysfunction and may compromise the ATP-dependent pathways supporting synaptic transmission. 
Table 2

CAT and SOD activities, GSH/GSSG ratio and ROS generation in brain mitochondria-free cytosolic fraction of nonTg and $3 \times \mathrm{Tg}-\mathrm{AD}$ mice

\begin{tabular}{lcc}
\hline & NonTg & $3 \times T g-A D$ \\
\hline $\begin{array}{l}\text { CAT (nmol O } \\
\text { protein) }\end{array}$ & $5581.67 \pm 554.10$ & $4788.85 \pm 106.60$ \\
$\begin{array}{l}\text { SOD (Uact/min/mg } \\
\text { protein) }\end{array}$ & $5.06 \pm 0.22$ & $4.99 \pm 0.32$ \\
GSH/GSSG & $1.87 \pm 0.58$ & $1.99 \pm 0.21$ \\
ROS (nmol DCF/mg & $8.78 \pm 0.34$ & $9.98 \pm 0.25^{*}$ \\
protein) & & \\
\hline
\end{tabular}

Results are expressed as mean \pm std of three independent experiments. * Significantly different from nonTg, with $p<0.05$.

\section{Phospholipid content of brain mitochondria}

In order to assess mitochondrial membrane lipid profile and evaluate its putative relationship with synaptic bioenergetic dysfunction detected in an $\mathrm{AD}$ animal model, phospholipids were extracted from nonsynaptic and synaptic mitochondria and analyzed by means of lipidomic approaches. Mitochondrial membrane phospholipid composition was accomplished through HPLC-MS.

It was possible to identify and quantify seven different phospholipid classes, namely LPC, as well as PC, SM, PE, PS, CL, PA, PG, and PI, in both mitochondria populations of $3 \times \mathrm{Tg}-\mathrm{AD}$ and nonTg matched controls (Fig. 3). The relative abundance of phospholipid classes of non-synaptic mitochon- drial membranes is similar in healthy and $3 \times \mathrm{Tg}-\mathrm{AD}$ mice brains and is characterized by $\mathrm{PC}, \mathrm{PE}$, and $\mathrm{CL}$ dominance which together represent more than $75 \%$ of all phospholipids (Fig. 3A). On the other hand, $3 \times$ Tg-AD synaptic mitochondria exhibited an altered phospholipid composition detected in choline phospholipids (PC and LPC) and CL contents (Fig. 3B). $\mathrm{PC}$ and $\mathrm{LPC}$ relative abundance is significantly higher in 3xTg-AD group (PC: nonTg 31.91 \pm 1.41 , 3xTg$\mathrm{AD} 39.84 \pm 3.34$; LPC: nonTg $0.78 \pm 0.29,3 \times \mathrm{xT}-\mathrm{AD}$ $1.63 \pm 0.68)$. Instead, synaptic mitochondrial CL content is significantly decreased in $3 \times \mathrm{Tg}-\mathrm{AD}$ animals regarding healthy controls (nonTg 18.20 \pm 1.38 , 3xTg$\mathrm{AD} 11.97 \pm 1.31)$.

\section{Phospholipid profile of synaptic brain mitochondria}

Lipid extracts of synaptic and non-synaptic mitochondria were analyzed using HPLC-MS/MS in both positive- and negative-ion modes. Typical positiveion ESI mass spectra and the relative abundance of most representative molecular species of cholinecontaining-phospholipids (i.e., PC, LPC, and SM) from synaptic mitochondria of nonTg and 3xTg-AD mice are shown in Fig. 4. Fatty acid diversity, obtained by analyzing the MS/MS fragmentation pattern of each ion, is depicted in Supplementary Table 3. Quantitative analysis of HPLC-MS spectra allowed the
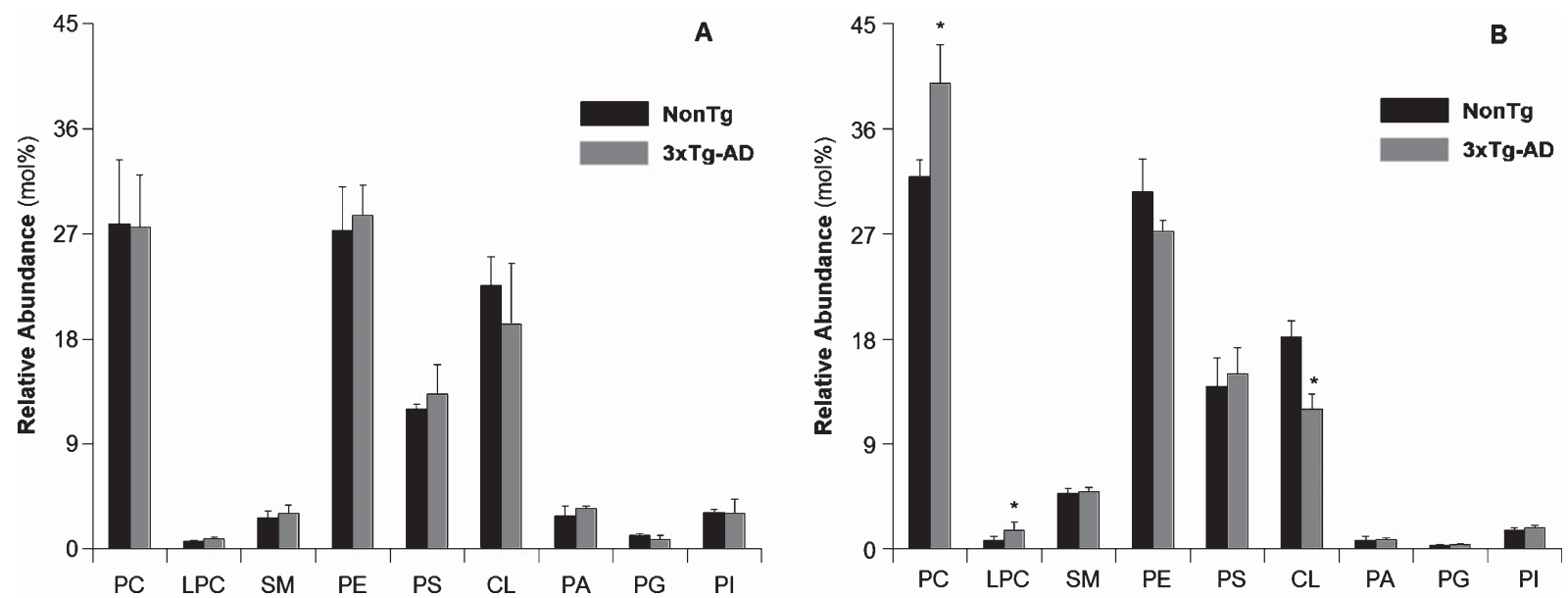

Fig. 3. Relative abundance (mol\%) of each phospholipid classes in total lipid extract obtained from non-synaptic (A) and synaptic (B) brain mitochondria isolated from nonTg (dark bars) and 3xTg-AD (gray bars) mice. PC phosphatidylcholine, LPC lyso-phosphatidylcholine, SM sphingomyelin, PE phosphatidylethanolamine, PS phosphatidylserine, CL cardiolipin, PA phosphatidic acid, PG phosphatidylglycerol, PI phosphatidylinositol. Error bars represent standard deviation for $n=3$ independent experiments using 3 animals each in each one. The amount of each phospholipid class was calculated by the sum of its individual species identified and quantified by HPLC-MS/MS, as described in methods section. Considering the results as total nmoles of phospholipids per mg of protein; non-synaptic mitochondria: nonTg $366.9 \pm 33.2$ and 3xTg-AD 384.2 \pm 30.3; synaptic mitochondria: nonTg 334.0 \pm 13.9 and 3xTg-AD 351.2 \pm 14.3 . *Significantly different from nonTg group, with $p \leq 0.05$. 


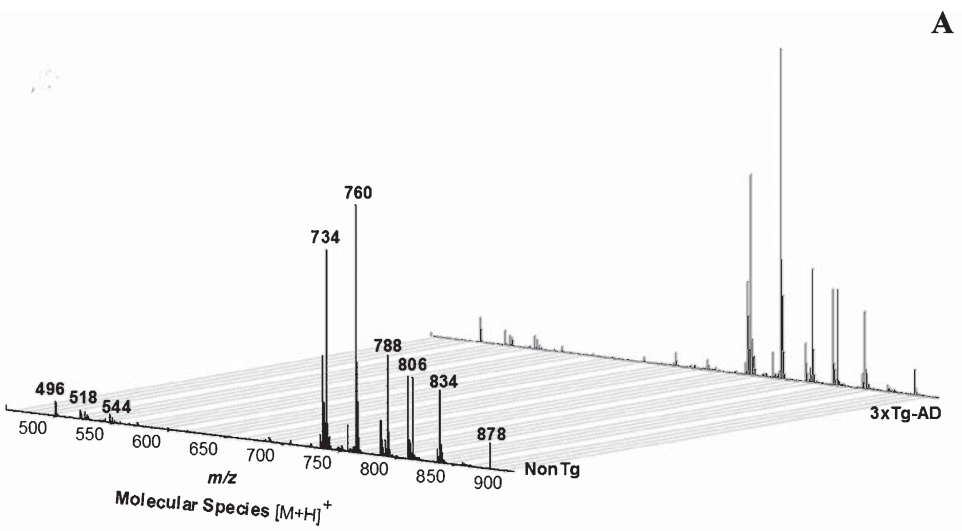

B
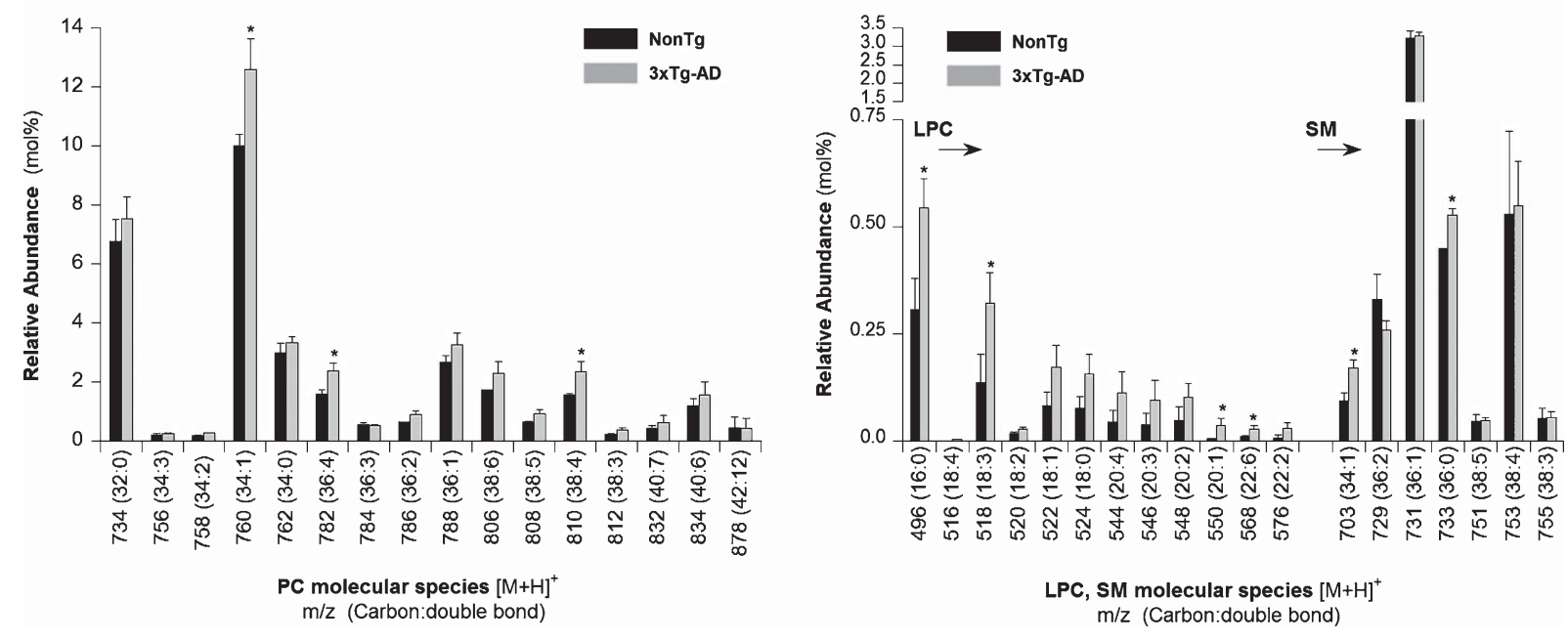

Fig. 4. Molecular profile of choline lipids extracted from nonTg (black bars) and 3xTg-AD (gray bars) synaptic mitochondria. A) Typical ESI-MS in positive mode with formation of $[\mathrm{M}+\mathrm{H}]^{+}$ions of PC, LPC, and SM. Distribution of (B) PC, (C) LPC and SM molecular species. Error bars represent standard deviation for $n=3$ independent experiments using 3 animals in each one. *Significantly different from nonTg group, with $p \leq 0.05$.

identification of $m / z 496$ (16:0), 731 (36:1), and 760 (34:1) as the predominant ions of LPC, SM, and PC phospholipid classes, respectively. Relative abundance of PC molecular ions at $m / z 760$ (34:1), 782 (36:4), and $810(38: 4)$ is increased in 3xTg-AD group compared to nonTg group (Fig. 4B). Indeed, PC molecular ion at $\mathrm{m} / \mathrm{z} 760$ (34:1) comprises higher fatty acid diversity in $3 x T g-A D$ PC (16:0/18:1) and PC (16:1/18:0) than in nonTg PC (16:0/18:1). In contrast, 3xTg-AD PC ions at $\mathrm{m} / \mathrm{z} 782(36: 4)$ and $810(38: 4)$ lose fatty acid diversity by lacking PC (18:0/18:4) and PC (18:1/20:3), respectively, as indicated in Supplementary Table 3. The relative abundance of LPC molecular ions at $\mathrm{m} / \mathrm{z}$ 496 (16:0), 518 (18:3), 550 (20:1), and 568 (22:6) and of SM molecular ions at $\mathrm{m} / \mathrm{z} 703$ (34:1) and
733 (36:0) was found to have increased in $3 \mathrm{xTg}-\mathrm{AD}$ synaptic mitochondria (Fig. 4C). Fatty acid composition of LPC and SM molecular ions was preserved in 3xTg-AD synaptic mitochondrial membranes compared to healthy controls (Supplementary Table 3). On the other hand, choline-containing-phospholipids profile of 3xTg-AD non-synaptic brain mitochondria was similar both in composition and diversity to that detected in nonTg matched controls (Supplementary Figure 2).

HPLC-MS/MS analyses were also performed in negative-ion mode in order to access the molecular profile of phospholipid classes PS, PE, PA, PG, PI, and $\mathrm{CL}$ from nonTg and 3xTg-AD synaptic mitochondrial membranes (Figs. 5 and 6). Typical ESI-MS 
$\mathbf{A}$ B
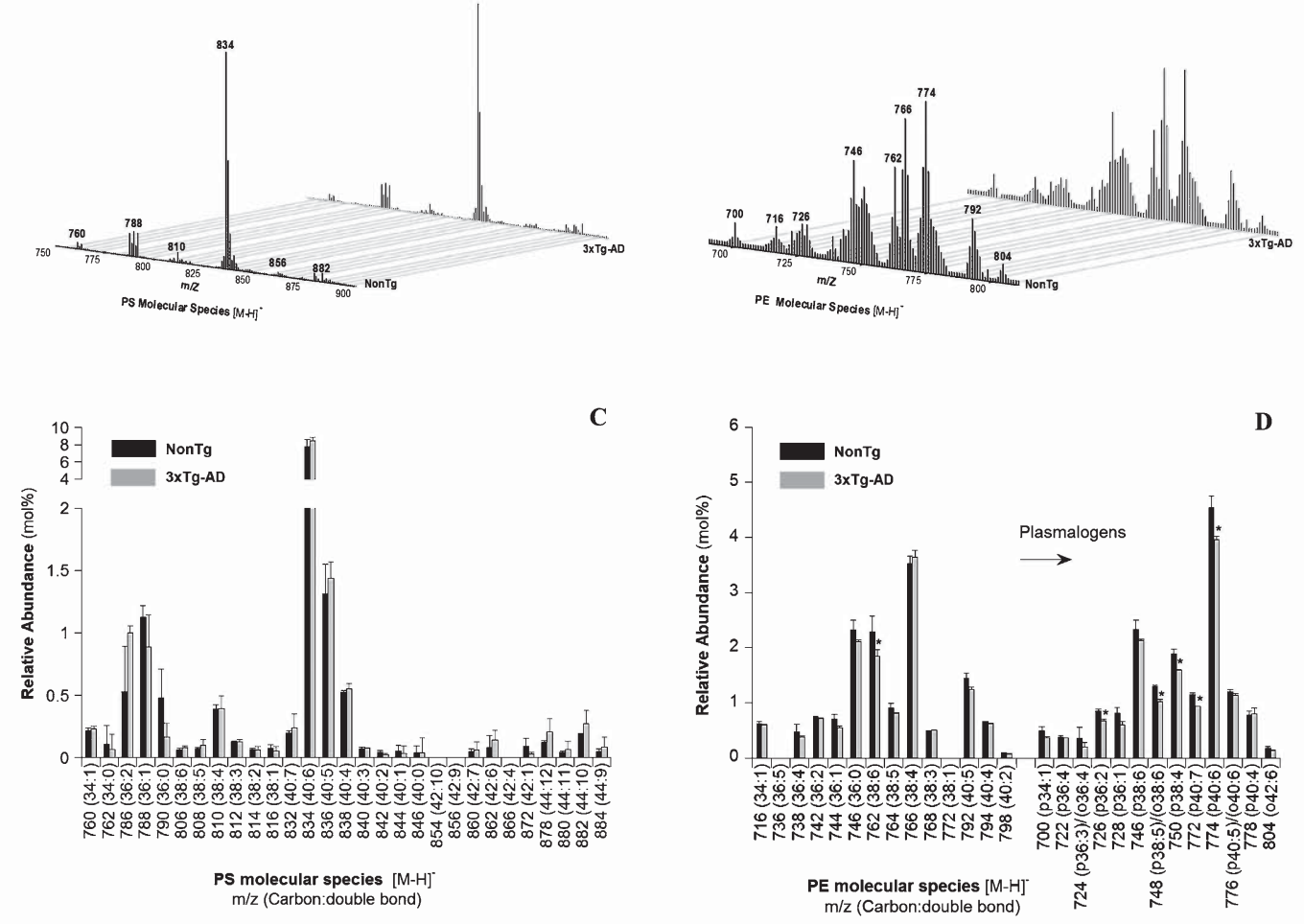

$\mathbf{E}$
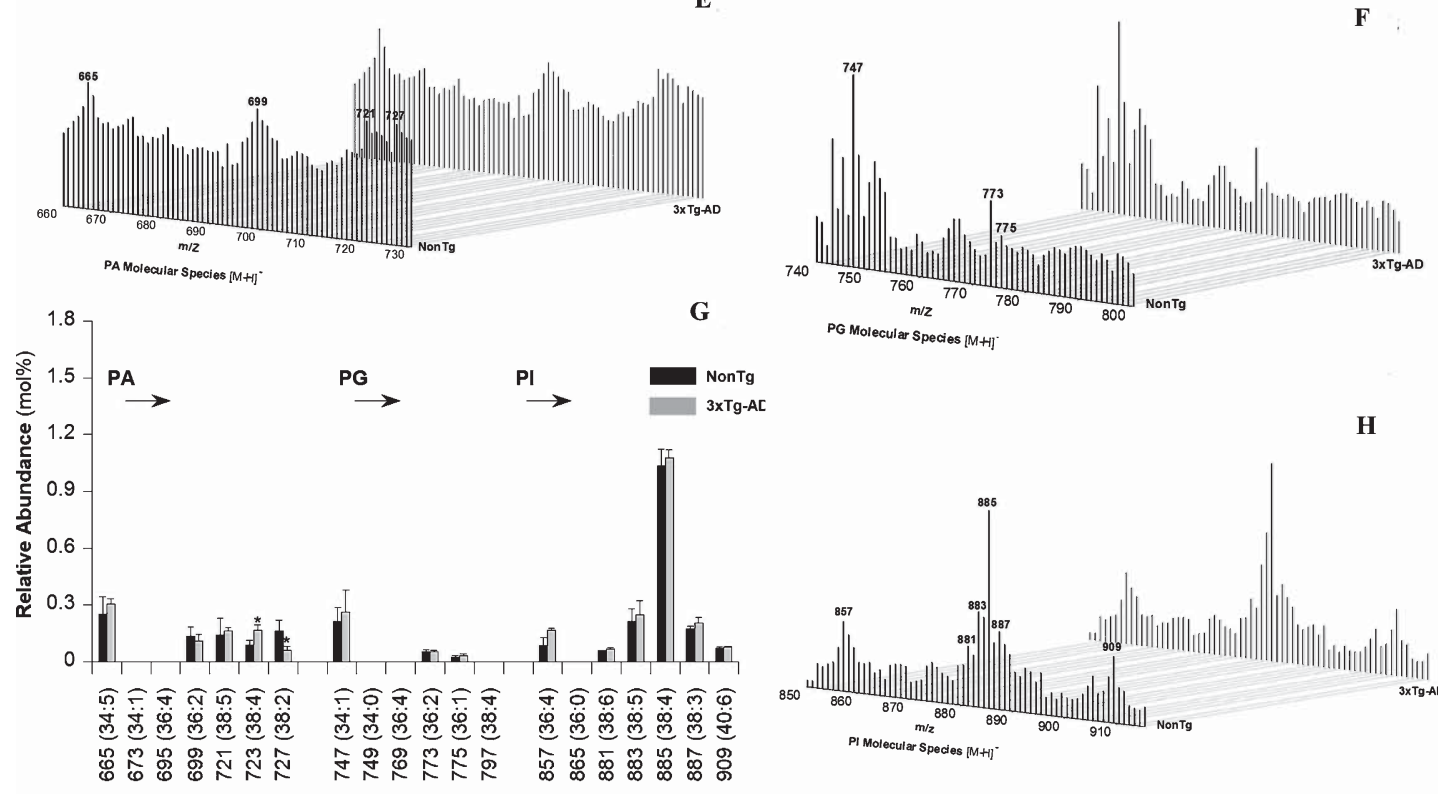

$\mathbf{H}$

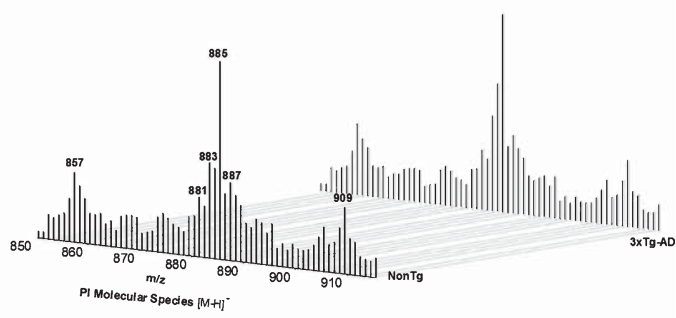

Molecular species $[\mathrm{M}-\mathrm{H}]$

$\mathrm{m} / \mathrm{z}$ (Carbon:double bond)

Fig. 5. Molecular profile of PS, PE, PA, PG, and PI extracted from nonTg (black bars) and 3xTg-AD (gray bars) synaptic mitochondria. Typical ESI-MS of (A) PS, (B) PE, (E) PA, (F) PG, and (H) PI obtained in negative ion-mode. Distribution of (C) PS and (D) PE, and (G) PA, PG, and PI molecular species. Error bars represent standard deviation for $n=3$ independent experiments using 3 animals in each one. *Significantly different from nonTg group, with $p \leq 0.05$. 


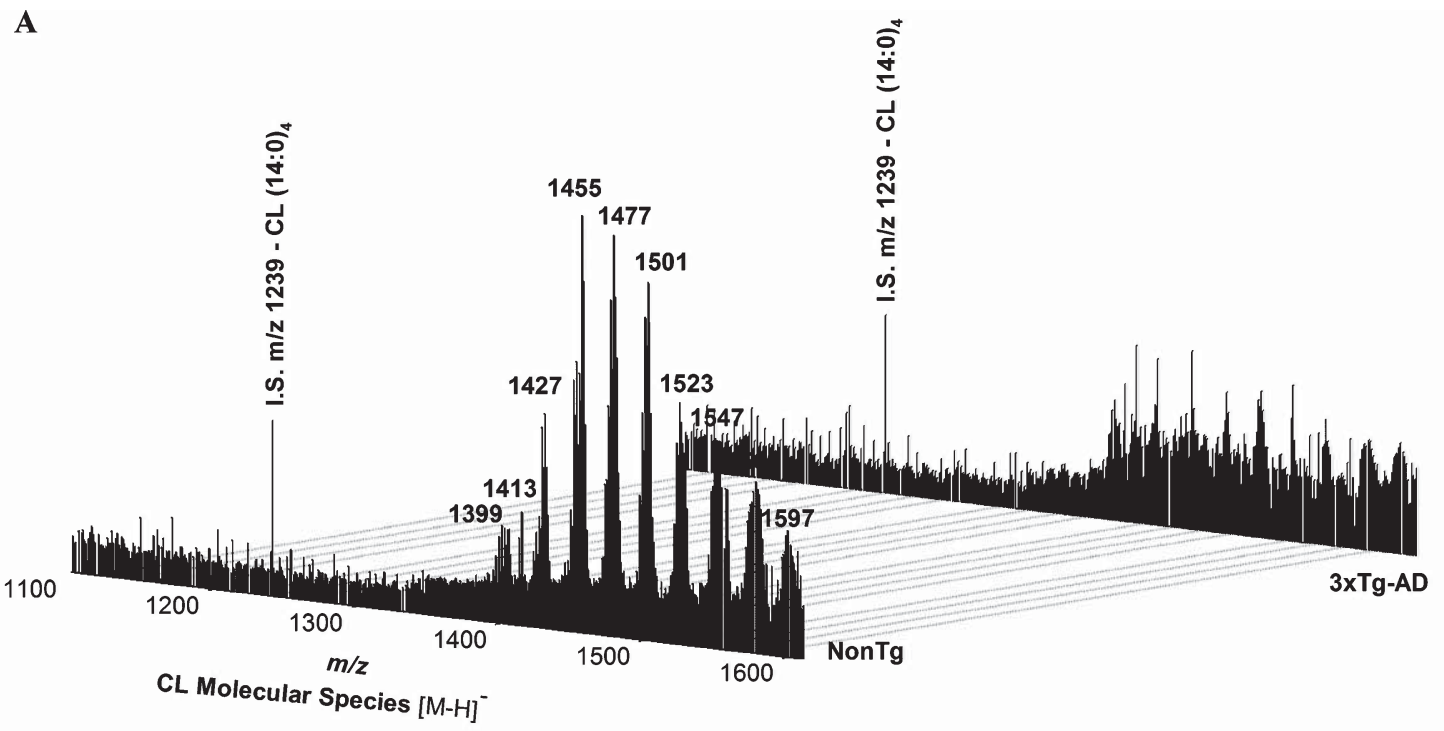

B

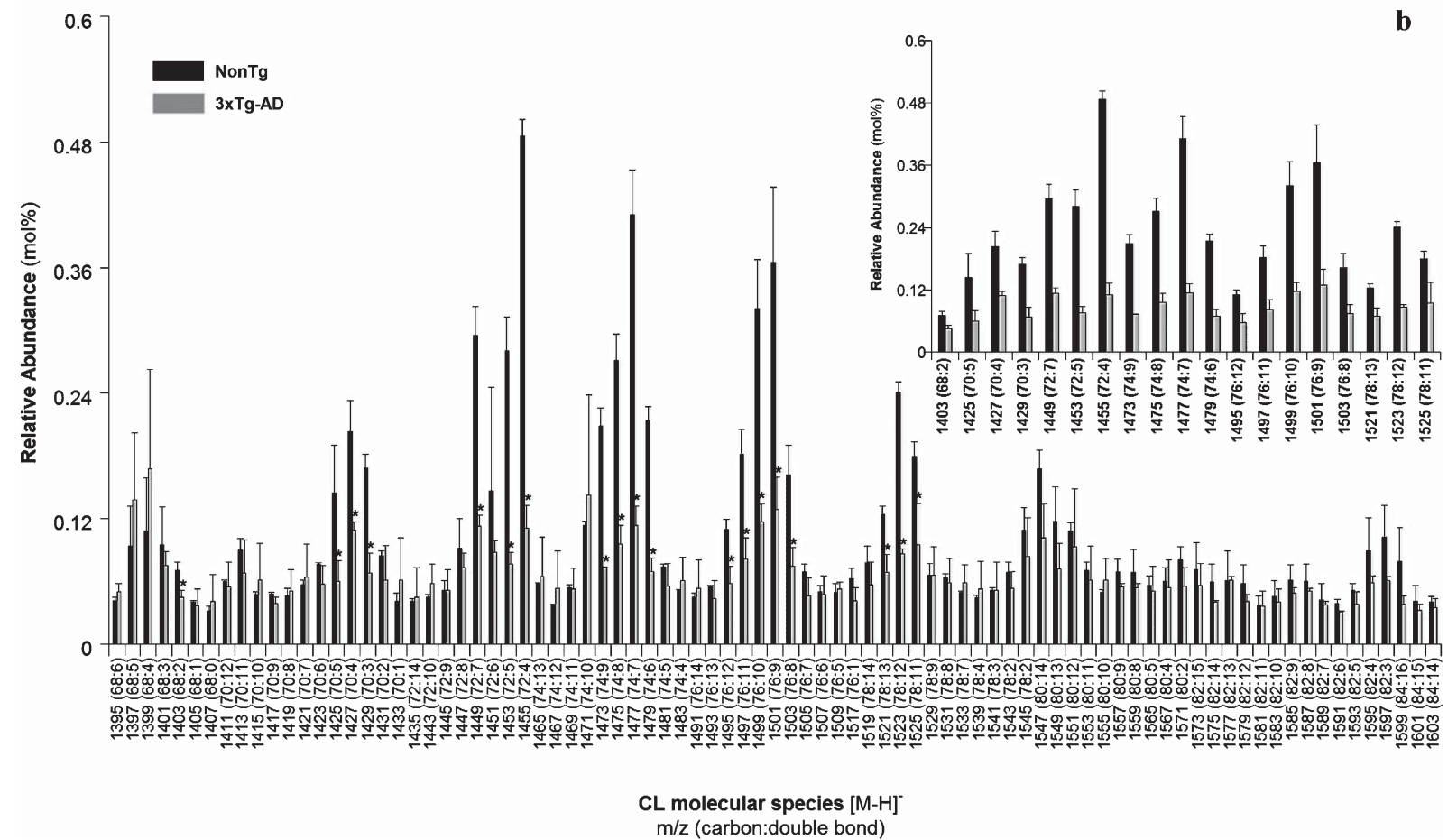

Fig. 6. Molecular profile of CL extracted from nonTg (black bars) and 3xTg-AD (gray bars) synaptic mitochondria. A) Typical ESI-MS of $\mathrm{CL}$ obtained in negative mode with formation of $[\mathrm{M}-\mathrm{H}]^{-}$ions. B) Distribution of CL molecular species with differences between nonTg and $3 \times \mathrm{xT}$-AD groups emphasized into insert (b). Error bars represent standard deviation for $n=3$ independent experiments using 3 animals in each one. *Significantly different from nonTg group, with $p \leq 0.05$.

spectra and correspondent quantifications of PS and $\mathrm{PE}$ molecular species are displayed in Fig. 5A-D. Data are consistent, revealing that ions at $\mathrm{m} / \mathrm{z} 834$
PS (40:6), 766 PE (38:4), and 774 PE plasmalogen ( $p 40: 6)$ are the most representative molecular species within the respective phospholipid class in synaptic 
brain mitochondria of both groups. Although PS profile of synaptic mitochondria was similar in both animal groups (Fig. 5A, C), PE profile showed significant changes, especially visible in the relative abundance of diacyl-PE species at $\mathrm{m} / \mathrm{z}, 762$ (38:6) and plasmalogens species at $m / z, 726$ (p36:2), 748 (p38:5, o38:6), 750 (p38:4), 772 (p40:7), and 774 (p40:6) in the 3xTg-AD group (Fig. 5D), in which they significantly decreased. Regarding the minor anionic phospholipids (Fig. 5E-H), they showed similar PA, PG, and PI profiles for both animal groups, although the relative abundance of PA ions at $\mathrm{m} / \mathrm{z} 723$ (16:0/22:4, 18:0/20:4) and 727 (18:1/20:1, 18:0/20:2) was higher and lower respectively, in $3 \times \mathrm{Tg}-\mathrm{AD}$ mice. The fatty acid diversity of each PS, PE, PA, PG, and PI molecular ions obtained from synaptic mitochondria is listed in Supplementary Tables 4-6.

Non-synaptic mitochondrial membranes showed no significant differences in the quantitative analysis of PS, PE, PA, PG, and PI molecular species (Supplementary Figure 5) with the exception of PE plasmalogen ion with $m / z 726$ (p36:2), whose relative abundance declined in the $3 \times \mathrm{Tg}-\mathrm{AD}$ group. In this mitochondria population, the pathological condition did not affect the fatty acid diversity in the phospholipid classes analyzed. Furthermore, the essential nature of fatty acid diversity within each phospholipid class was similar in both nonTg brain mitochondrial populations.

\section{CL analysis}

CL is a unique tetra-acyl phospholipid found almost exclusively in the inner mitochondrial membranes and is essential for maintaining mitochondrial functionality and membrane integrity [43]. Specifically, CL has shown to be required for the proper structure and activity of mitochondrial electron transport chain enzymes [22, 44]. Not surprisingly, due to its importance in mitochondrial function, alteration of normal CL metabolism has been associated with several pathologies, including neurodegenerative diseases [43]. CL profiling observed in MS spectra of nonTg and 3xTg-AD synaptic mitochondria are shown in Fig. 6A. NonTg singly charged $[\mathrm{M}-\mathrm{H}]^{-}$ions, correspondent to CL molecular species, are represented at least by seven major clusters with a variety of fatty acid residues in synaptic mitochondria. Interestingly, this pattern was lost in MS spectrum obtained for CL of 3xTg-AD synaptic mitochondria, mainly due to a decline in the most representative molecular specie within each cluster, as reflected in CL molecular species quantification (Fig. 6B, b). Additionally, in MS spectra of Fig. 6A, monolysocardiolipins were not detected in synaptic mitochondria of either nonTg and 3xTg-AD mice, since in $m / z$ region, between 1100 and 1380 , only the species with $\mathrm{m} / z$ at 1239 (internal standard, CL(14:0)4) reach the minimum intensity to be identified. Despite the aberrant CL profile exhibited by 3xTg-AD synaptic mitochondria, the molecular species diversity was preserved (Supplementary Table 7).

Detailed analyses were performed in order to better understand the putative functional impact of this aberrant CL profile on mitochondrial membranes, taking into consideration the number of unsaturated bounds (Fig. 7A) and the carbon chain length (Fig. 7B), as well as the differences between the aberrant $\mathrm{CL}$
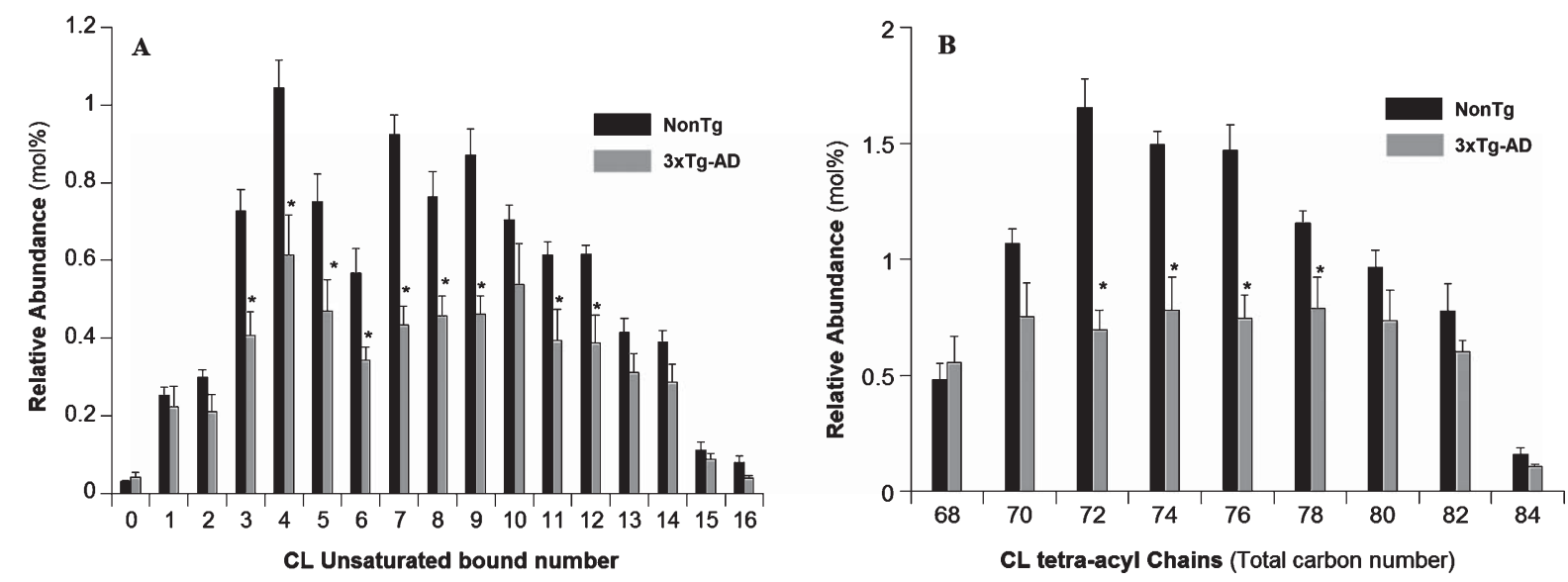

Fig. 7. CL distribution as functions of total number of double bounds (A) and chain length (B) considering the sum of the four CL acyl chains in synaptic mitochondria isolated from nonTg (black bars) and 3xTg-AD (gray bars) mice. *Significantly different from nonTg group, with $p \leq 0.05$. 
profile exhibited by $3 \times \mathrm{Tg}$-AD synaptic mitochondria and the predicted CL profile, bearing in mind that the decreased CL content exhibited by synaptic mitochondria of 3xTg-AD mice occurs only as a function of the relative abundance of each CL species in nonTg mice (Supplementary Figure 6). These data show a decrease of specific CL species regarding the number of unsaturated bounds and carbon chain length, which points to a tendency toward normalization of its relative abundance. In other words, the predominant CL species with a specific number of unsaturated bounds or with a specific carbon chain length that were found in the nonTg group disappeared in the $3 \times \mathrm{Tg}-\mathrm{AD}$ group, reaching a relative abundance that is similar to the one observed among minor CL species. Therefore, the abnormal CL profile of synaptic mitochondria of $3 \times \mathrm{Tg}-\mathrm{AD}$ mice does not result from a regular decrease associated with low levels of total CL content in this group.

CL profile of non-synaptic mitochondria was also analyzed by MS; the differences between nonTg and $3 \times \mathrm{Tg}-\mathrm{AD}$ groups found in this mitochondria population are not as extensive as those found in synaptic mitochondria (Supplementary Figure 4). In fact, the CL profile of non-synaptic mitochondria is just affected by the pathological situation of some CL molecular species, namely the ones that correspond to $[\mathrm{M}-\mathrm{H}]^{-}$ ions at $\mathrm{m} / z 1399$ (68:4); 1421 (70:7); 1423 (70:6); 1447 (72:8); 1453 (72:5); 1517 (76:1); and 1531 (78:8), whose relative abundance differs from that of the nonTg group. Additionally, fatty acid diversity within each CL species is similar in both non-synaptic and synaptic brain mitochondria from nonTg mice (Supplementary Table 7).

\section{Brain oxidative stress state and acetylcholinesterase activity}

In order to characterize the overall redox state of 3-month old nonTg and 3xTg-AD mice brains, we evaluated the activity of antioxidant enzymes (SOD and CAT), GSH and GSSG contents, and ROS levels generated by brain mitochondria-free cytosolic fractions. Table 2 shows that SOD and CAT activities and GSH and GSSG levels are similar in nonTg and 3xTg-AD groups. Nevertheless, in 3xTg-AD brains, a significant increase in ROS levels was observed (13\%) compared to nonTg group, which indicates oxidative stress events are more likely to occur in $3 \times \mathrm{Tg}-\mathrm{AD}$ group.

AChE activity was also evaluated in the brain mitochondria-free cytosolic fractions, since its phar- macological modulation is a usual therapeutic strategy used in AD. Although AChE activity was slightly increased in 3xTg-AD brains, the Michaelis-Menten enzymatic kinetics parameters $\left(\mathrm{V}_{\max }\right.$ and $\left.\mathrm{Km}\right)$ were not significantly different from nonTg matched controls, as shown in Supplementary Figure 5.

\section{DISCUSSION}

The dynamic regulation of brain functions requires a high energy flux dependent on both glucose metabolism and mitochondrial function [45]. In this way, brain bioenergetic decline has been involved in the neurodegenerative pathways and consequent synaptic failure in $\mathrm{AD}[37,46]$. In the present study, bioenergetic analyses revealed the existence of dysfunctional synaptic mitochondria associated with the decay of complex I activity which contributes to ATP deficit and an increased phosphorylated AMPK/AMPK total ratio detected in 3xTg-AD brains (Table 1 and Fig. 1). This brain energy deficit promotes AMPK activation, triggering not only a metabolic reprogramming to restore the brain energy homeostasis but also changes in cell signaling pathways connected to mitochondrial biogenesis and autophagy [47]. Therefore, at an early stage of $\mathrm{AD}$, brain mitochondrial dysfunctions are primarily detected in synaptic mitochondria that precede the extracellular deposition of $A \beta$ and the formation of intracellular neurofibrillary tangles [24]. This is concurrent with the report by Yao and collaborators of a brain mitochondrial respiration impairment and decreased pyruvate dehydrogenase protein levels in 3-month old 3xTg-AD female mice [48]. Alterations of brain mitochondrial functions were also detected in 3-month old Thy-1 A $\beta$ PP mice, characterized by a decrease in mitochondrial transmembrane potential and ATP levels [49]. A more detailed study, using the same mice model, showed that brain mitochondria functionality disruption associated with declined complex IV activity is earlier detected in synaptic population [46]. Postmortem analysis of brain tissue from AD patients also detected anomalous complex IV and pyruvate dehydrogenase expression and activities [50], highlighting the role of mitochondrial dysfunctions in disease pathogenesis.

The differences in CS normalized complex I activity detected in the synaptic mitochondria of nonTg and $3 \times \mathrm{Tg}-\mathrm{AD}$ mice may result from several factors, including: i) selective changes in the relative complex I membrane content as a consequence of downregulation of protein expression and/or synthesis; and ii) changes 
in the lipid composition of mitochondrial membranes which regulate the membrane assembling and activity of mitochondrial enzymes complexes [19, 20, 33]. Complex I (similarly to complexes III and IV and FoF1-ATPsynthase) is a multi-subunit enzyme with some subunits encoded by mitochondrial DNA and others (majority) encoded by nuclear genome, which are mainly synthesized in perinuclear cellular regions. The spatiotemporal distribution of mitochondria in neurons is dynamically regulated by mitochondrial traffic through axon that includes mitochondria either moving primarily anterogradely and retrogradely or appearing to be stationary for an extended period in cellular regions with high ATP demand (e.g., synapses) [51]. Since complex I activity in non-synaptic mitochondria is similar in both nonTg and 3xTg-AD mice, problems affecting protein expression and/or synthesis can be ruled out. Thus, it was our concern to ascertain whether 3xTg-AD brain bioenergetic deficit associated with decreased complex I activity was correlated with changes in the phospholipid composition of synaptic mitochondrial membranes. Data from lipidomic analyses show that $3 \times \mathrm{Tg}$-AD synaptic mitochondria exhibit an altered phospholipid composition at two levels of complexity, characterized by: i) decrease of CL content with a concomitant increase of choline phospholipids (PC and LPC); ii) altered PC, LPC, PE (mainly plasmalogens), and CL molecular profiles. It is interesting to note that changes of phospholipid class content were not random but resulted from modifications in the relative abundance of specific molecular species, as is clearly evidenced by LPC (Fig. 4), ethanolamine plasmalogens (Fig. 5), and CL (Fig. 6) profiles.

The higher LPC content suggests that intracellular phospholipases $\mathrm{A}_{2}\left(\mathrm{iPLA}_{2}\right)$ may be upregulated in synaptic bottom of neurons of transgenic animals with an expected impact on lipid singling processes. Detailed analysis of LPC diversity (Supplementary Table 3) supports the idea that increased membrane LPC at $m / z$ 496, 520, 522, 524, and 546 may result from hydrolysis of PC at $m / z$ 782, 806, 808, 810, and 832 by iPLA $_{2}$ with the consequent release of free arachidonic acid (C20:4), a well-known precursor of pro-inflammatory lipid signaling molecules, such as prostaglandins and thromboxanes. In fact, increased LPC content and oxidized derivatives of arachidonic acid have been involved in brain inflammatory processes which are characteristic of $\operatorname{AD}[52,53]$.

Ethanolamine plasmalogens seem to be essential to preserve the functional organization of the membrane and protect it against oxidative stress [54]. The functional relevance of membrane plasmalogens is also well evidenced by the positive relationship between low levels of brain membrane plasmalogens and severe human dementia [55]. Brain mitochondria plasmalogens comprise about $50 \%$ of PE content; however, their specific role in brain mitochondria function remains poorly understood. Profile changes in ethanolamine plasmalogens found in synaptic mitochondria of 3xTg-AD mice, occurring simultaneously with mitochondrial bioenergetic deficits, may contribute to the characteristic metabolic phenotype of AD.

CL, a specific mitochondrial phospholipid, is synthesized from condensation of PG and cytidinediphosphate-diacylglycerol (CDP-DAG) to form immature CL [18]. However, the functional mitochondrial CL profile results from remodeling processes that involve sequential phospholipase (deacylation) and transacylase/acyltransferase activities and use PE, PC, and Acyl-CoA as fatty acids donor to produce mature species [56]. CL content and diversity are intimately linked to functional membrane assembly of redox complexes of the respiratory system and phosphorylation apparatus regulating cells' energetic requirements [20,44]. Besides, the brain exhibits a CL profile with the highest molecular diversity, comprising about 100 different species organized in at least seven clusters $[19,57]$. These are eventually necessary to support the highly dynamic energy flux required for its proper functioning. 3xTg-AD synaptic mitochondria lose the CL cluster-organized profile due to a decline of the most representative molecular species, which may have functional consequences. In this view, decreased CL content shown in 3xTg-AD synaptic mitochondria (Fig. 6) may reflect a decrease in CL synthase activity and/or expression, or enhanced CL degradation pathways. Since CL profile of nonsynaptic brain mitochondria of $3 \times \mathrm{Tg}-\mathrm{AD}$ mice is similar to that exhibited by nonTg mice (Supplementary Figure 4), CL synthase expression and/or activity should, therefore, not be affected. Therefore, the decline of more representative CL species may result from changes in remodeling pathways or increased degradation of selective species.

The pathological role of altered CL metabolism associated with mitochondrial dysfunction and increased mitochondrial apoptotic cascade pathway has been documented in several disorders, such Barth Syndrome. In those cases, the alteration of CL profile is believed to be the primary molecular manifestation emerging from tafazzin deficiency [58]. Along with iPLA $_{2}$, tafazzin is considered a key enzyme in CL remodeling process and its cellular deficiency is 
characterized by an increase of monolyso-cardiolipin levels and a decrease of CL content and of the average number of double bonds per cardiolipin molecule [59]. Although 3xTg-AD synaptic mitochondria exhibit an aberrant CL profile and lower CL content, the average number of double bonds per cardiolipin molecule (7.6) is similar to that found in nonTg synaptic brain mitochondria (Fig. 7).

CL content loss also contributes to the age-related phenotype generally associated with mitochondrial dysfunction and oxidative stress [60]. Our results indicate that 3-month old 3xTg-AD mice are able to preserve brain redox state as suggested by GSH/GSSG ratio and CAT and SOD activities (Table 2). In turn, the augmented ROS generation detected in $3 \times \mathrm{Tg}$ AD brains (Table 2) could lead to a ROS-dependent oxidation of selective molecules, with a putative contribution to the abnormal CL profile. However, the mitochondrial accumulation of oxidized CL should not be particularly relevant, since those species were neither detected by HPLC-MS/MS analyses of total lipid extracts nor by direct ESI-MS/MS analyses of TLC obtained CL.

Taken together, bioenergetic and lipidomic data support the idea that synaptic mitochondrial dysfunction, resulting essentially from a decay of complex I activity, and an aberrant mitochondrial membrane phospholipid composition, mainly detected in CL profile, are interconnected key players contributing to the energetic deficit detected in early stages of AD.

Lipid and mitochondrial bioenergetic metabolisms are functionally interdependent and our data, obtained at the age of three months, do not allow us to discriminate where the dysfunction first occurs. Thus, synaptic mitochondrial lipid changes and bioenergetic deficit may compromise the ATP-dependent biochemical pathways with several functional consequences, including the loss of lipid asymmetry in synaptic membrane. The loss of lipid asymmetry increases the concentration of aminophospholipids (PS and PE) in the outer leaflet of the membrane, leading to a decrease in the inner leaflet, with two main consequences: i) changes in the lateral membrane organization, making A $\beta P P$ accessible to hydrolysis by BACE and causing $\mathrm{A} \beta$ formation ( $\mathrm{A} \beta$ pathology); and ii) decrease of the negative charge density on the cytosolic surface of the synaptic membrane, lessening its ability to bind and regulate intracellular $\mathrm{Ca}^{2+}$ fluxes that are instrumental in releasing neurotransmitters and an increase of free cytosolic $\mathrm{Ca}^{2+}$ and the associated neurotoxicity (e.g., tau pathology and upregulation of calcium-dependent iPLA $_{2}$ ).
To conclude, our study is pioneer insofar as it shows, for the first time, that synaptic mitochondrial defects concomitant with extensive alterations in CL profile represent key early alterations in the development of AD. In fact, dysfunction of synaptic mitochondria and energy depletion associated to a loss of lipid asymmetry contribute to $A \beta$ accumulation and cell dysfunction.

\section{ACKNOWLEDGMENTS}

This work was supported by Foundation for Science and Technology (FCT), and European Union Funds (FEDER/COMPETE) [Project Grants: PTDC/SAUNMC/115865/2009; PEst-C/QUI/UI0062/2013 - FCO MP-01-0124-FEDER-037296; PEst-OE/QUI/UI06 $16 / 2014$ and the Portuguese National Mass Spectrometry Network]. Vera F. Monteiro-Cardoso is supported by FCT grant BI/PTDC/SAU NMC/115865/2009 and Tânia Melo by FCT grant SFRH/BD/84691/2012.

Authors' disclosures available online (http://www.jalz.com/disclosures/view.php?id=2480).

\section{SUPPLEMENTARY MATERIAL}

The supplementary material is available in the electronic version of this article: http://dx.doi.org/ 10.3233/JAD-141002.

\section{REFERENCES}

[1] Yetukuri L, Ekroos K, Vidal-Puig A, Oresic M (2008) Informatics and computational strategies for the study of lipids. Mol Biosyst 4, 121-127.

[2] van Meer G, Voelker DR, Feigenson GW (2008) Membrane lipids: Where they are and how they behave. Nat Rev Mol Cell Biol 9, 112-124.

[3] Moller DE, Kaufman KD (2005) Metabolic syndrome: A clinical and molecular perspective. Annu Rev Med 56, 45-62.

[4] Wallace DC (2005) A mitochondrial paradigm of metabolic and degenerative diseases, aging, and cancer: A dawn for evolutionary medicine. Annu Rev Genet 39, 359-407.

[5] Serrano-Pozo A, Frosch MP, Masliah E, Hyman BT (2011) Neuropathological alterations in Alzheimer disease. Cold Spring Harb Perspect Med 1, a006189.

[6] Contestabile A (2011) The history of the cholinergic hypothesis. Behav Brain Res 221, 334-340.

[7] LaFerla FM (2002) Calcium dyshomeostasis and intracellular signalling in Alzheimer's disease. Nat Rev Neurosci 3, 862872.

[8] Puglielli L, Tanzi RE, Kovacs DM (2003) Alzheimer's disease: The cholesterol connection. Nat Neurosci 6, 345-351.

[9] Karran E, Mercken M, De Strooper B (2011) The amyloid cascade hypothesis for Alzheimer's disease: An appraisal for the development of therapeutics. Nat Rev Drug Discov 10 , 698-712. 
[10] Arispe N, Diaz JC, Simakova O (2007) Abeta ion channels. Prospects for treating Alzheimer's disease with Abeta channel blockers. Biochim Biophys Acta 1768, 1952-1965.

[11] Hattori C, Asai M, Onishi H, Sasagawa N, Hashimoto Y, Saido TC, Maruyama K, Mizutani S, Ishiura S (2006) BACE1 interacts with lipid raft proteins. J Neurosci Res $\mathbf{8 4}$, 912-917.

[12] McLean CA, Cherny RA, Fraser FW, Fuller SJ, Smith MJ, Beyreuther K, Bush AI, Masters CL (1999) Soluble pool of Abeta amyloid as a determinant of severity of neurodegeneration in Alzheimer's disease. Ann Neurol 46, 860-866.

[13] Aleardi AM, Benard G, Augereau O, Malgat M, Talbot JC, Mazat JP, Letellier T, Dachary-Prigent J, Solaini GC, Rossignol R (2005) Gradual alteration of mitochondrial structure and function by beta-amyloids: Importance of membrane viscosity changes, energy deprivation, reactive oxygen species production, and cytochrome c release. J Bioenerg Biomembr 37, 207-225.

[14] Swerdlow RH, Khan SM (2004) A "mitochondrial cascade hypothesis" for sporadic Alzheimer's disease. Med Hypotheses 63, 8-20.

[15] Swerdlow RH, Burns JM, Khan SM (2010) The Alzheimer's disease mitochondrial cascade hypothesis. J Alzheimers Dis 20(Suppl 2), S265-S279.

[16] Moreira PI, Carvalho C, Zhu X, Smith MA, Perry G (2010) Mitochondrial dysfunction is a trigger of Alzheimer's disease pathophysiology. Biochim Biophys Acta 1802, 2-10.

[17] Resende R, Moreira PI, Proenca T, Deshpande A, Busciglio J, Pereira C, Oliveira CR (2008) Brain oxidative stress in a tripletransgenic mouse model of Alzheimer disease. Free Radic Biol Med 44, 2051-2057.

[18] Schwall CT, Greenwood VL, Alder NN (2012) The stability and activity of respiratory Complex II is cardiolipindependent. Biochim Biophys Acta 1817, 1588-1596.

[19] Melo T, Videira RA, Andre S, Maciel E, Francisco CS, Oliveira-Campos AM, Rodrigues LM, Domingues MR, Peixoto F, Manuel Oliveira M (2012) Tacrine and its analogues impair mitochondrial function and bioenergetics: A lipidomic analysis in rat brain. $J$ Neurochem 120, 998-1013.

[20] Kiebish MA, Han X, Cheng H, Chuang JH, Seyfried TN (2008) Cardiolipin and electron transport chain abnormalities in mouse brain tumor mitochondria: Lipidomic evidence supporting the Warburg theory of cancer. J Lipid Res 49 , 2545-2556.

[21] Osman C, Voelker DR, Langer T (2011) Making heads or tails of phospholipids in mitochondria. J Cell Biol 192, 7-16.

[22] Zhang M, Mileykovskaya E, Dowhan W (2002) Gluing the respiratory chain together. Cardiolipin is required for supercomplex formation in the inner mitochondrial membrane. $J$ Biol Chem 277, 43553-43556.

[23] Oddo S, Caccamo A, Kitazawa M, Tseng BP, LaFerla FM (2003) Amyloid deposition precedes tangle formation in a triple transgenic model of Alzheimer's disease. Neurobiol Aging 24, 1063-1070.

[24] Oddo S, Caccamo A, Shepherd JD, Murphy MP, Golde TE, Kayed R, Metherate R, Mattson MP, Akbari Y, LaFerla FM (2003) Triple-transgenic model of Alzheimer's disease with plaques and tangles: Intracellular Abeta and synaptic dysfunction. Neuron 39, 409-421.

[25] Hammer DF, Unverferth DV, Kelley RE, Harvan PA, Altschuld RA (1988) Extraction and measurement of myocardial nucleotides, nucleosides, and purine bases by high-performance liquid chromatography. Anal Biochem 169, 300-305.
[26] Gornall AG, Bardawill CJ, David MM (1949) Determination of serum proteins by means of the biuret reaction. J Biol Chem 177, 751-766.

[27] Spitz DR, Oberley LW (1989) An assay for superoxide dismutase activity in mammalian tissue homogenates. Anal Biochem 179, 8-18.

[28] Del Rio LA, Ortega MG, Lopez AL, Gorge JL (1977) A more sensitive modification of the catalase assay with the Clark oxygen electrode. Application to the kinetic study of the pea leaf enzyme. Anal Biochem 80, 409-415.

[29] Hissin PJ, Hilf R (1976) A fluorometric method for determination of oxidized and reduced glutathione in tissues. Anal Biochem 74, 214-226.

[30] Lima FD, Stamm DN, Della-Pace ID, Dobrachinski F, de Carvalho NR, Royes LF, Soares FA, Rocha JB, Gonzalez-Gallego J, Bresciani G (2013) Swimming training induces liver mitochondrial adaptations to oxidative stress in rats submitted to repeated exhaustive swimming bouts. PLoS One 8, e55668.

[31] Menassol JB, Tautou C, Collet A, Chesneau D, Lomet D, Dupont J, Malpaux B, Scaramuzzi RJ (2011) The effect of an intracerebroventricular injection of metformin or AICAR on the plasma concentrations of melatonin in the ewe: Potential involvement of AMPK? BMC Neurosci 12, 76.

[32] Kiebish MA, Han X, Cheng H, Lunceford A, Clarke CF, Moon $\mathrm{H}$, Chuang JH, Seyfried TN (2008) Lipidomic analysis and electron transport chain activities in C57BL/6J mouse brain mitochondria. J Neurochem 106, 299-312.

[33] Monteiro-Cardoso VF, Silva AM, Oliveira MM, Peixoto F, Videira RA (2014) Membrane lipid profile alterations are associated with the metabolic adaptation of the Caco- 2 cells to aglycemic nutritional condition. J Bioenerg Biomembr 46 , 45-57.

[34] Madeira VM, Antunes-Madeira MC, Carvalho AP (1974) Activation energies of the ATPase activity of sarcoplasmic reticulum. Biochem Biophys Res Commun 58, 897-904.

[35] Bartlett EM, Lewis DH (1970) Spectrophotometric determination of phosphate esters in the presence and absence of orthophosphate. Anal Biochem 36, 159-167.

[36] Doria ML, Cotrim Z, Macedo B, Simoes C, Domingues P, Helguero L, Domingues MR (2012) Lipidomic approach to identify patterns in phospholipid profiles and define class differences in mammary epithelial and breast cancer cells. Breast Cancer Res Treat 133, 635-648.

[37] Ding F, Yao J, Rettberg JR, Chen S, Brinton RD (2013) Early decline in glucose transport and metabolism precedes shift to ketogenic system in female aging and Alzheimer's mouse brain: Implication for bioenergetic intervention. PLoS One $\mathbf{8}$, e79977.

[38] Mosconi L, Mistur R, Switalski R, Tsui WH, Glodzik L, Li Y, Pirraglia E, De Santi S, Reisberg B, Wisniewski T, de Leon MJ (2009) FDG-PET changes in brain glucose metabolism from normal cognition to pathologically verified Alzheimer's disease. Eur J Nucl Med Mol Imaging 36, 811-822.

[39] Minoshima S, Giordani B, Berent S, Frey KA, Foster NL, Kuhl DE (1997) Metabolic reduction in the posterior cingulate cortex in very early Alzheimer's disease. Ann Neurol 42, 8594.

[40] Iglesias-Gonzalez J, Sanchez-Iglesias S, Beiras-Iglesias A, Soto-Otero R, Mendez-Alvarez E (2013) A simple method for isolating rat brain mitochondria with high metabolic activity: Effects of EDTA and EGTA. J Neurosci Methods 213, 39-42.

[41] Gellerich FN, Deschauer M, Chen Y, Muller T, Neudecker S, Zierz S (2002) Mitochondrial respiratory rates and activities of respiratory chain complexes correlate linearly with 
heteroplasmy of deleted mtDNA without threshold and independently of deletion size. Biochim Biophys Acta 1556, 41-52.

[42] Monteiro-Cardoso VF, Olivera MM, Peixot F, Videira RA (2013) Brain synaptic mitochondria dysfunction: An early event in triple-transgenic mice model of Alzheimer's disease. Eur J Clin Invest 43 44-44.

[43] Chicco AJ, Sparagna GC (2007) Role of cardiolipin alterations in mitochondrial dysfunction and disease. Am J Physiol Cell Physiol 292, C33-C44.

[44] Claypool SM (2009) Cardiolipin, a critical determinant of mitochondrial carrier protein assembly and function. Biochim Biophys Acta 1788, 2059-2068.

[45] Boumezbeur F, Mason GF, de Graaf RA, Behar KL, Cline GW, Shulman GI, Rothman DL, Petersen KF (2010) Altered brain mitochondrial metabolism in healthy aging as assessed by in vivo magnetic resonance spectroscopy. J Cereb Blood Flow Metab 30, 211-221.

[46] Du H, Guo L, Yan S, Sosunov AA, McKhann GM, Yan SS (2010) Early deficits in synaptic mitochondria in an Alzheimer's disease mouse model. Proc Natl Acad Sci U S A 107, 18670-18675.

[47] Ronnett GV, Ramamurthy S, Kleman AM, Landree LE, Aja $S$ (2009) AMPK in the brain: Its roles in energy balance and neuroprotection. J Neurochem 109(Suppl 1), 17-23.

[48] Yao J, Irwin RW, Zhao L, Nilsen J, Hamilton RT, Brinton RD (2009) Mitochondrial bioenergetic deficit precedes Alzheimer's pathology in female mouse model of Alzheimer's disease. Proc Natl Acad Sci U S A 106, 14670-14675.

[49] Hauptmann S, Scherping I, Drose S, Brandt U, Schulz KL, Jendrach M, Leuner K, Eckert A, Muller WE (2009) Mitochondrial dysfunction: An early event in Alzheimer pathology accumulates with age in AD transgenic mice. Neurobiol Aging 30, 1574-1586.

[50] Blass JP, Sheu RK, Gibson GE (2000) Inherent abnormalities in energy metabolism in Alzheimer disease. Interaction with cerebrovascular compromise. Ann N Y Acad Sci 903, 204-221.

[51] Schwarz TL (2013) Mitochondrial trafficking in neurons. Cold Spring Harb Perspect Biol 5, pii: a011304.
[52] Frisardi V, Panza F, Seripa D, Farooqui T, Farooqui AA (2011) Glycerophospholipids and glycerophospholipid-derived lipid mediators: A complex meshwork in Alzheimer's disease pathology. Prog Lipid Res 50, 313-330.

[53] Sundaram JR, Chan ES, Poore CP, Pareek TK, Cheong WF, Shui G, Tang N, Low CM, Wenk MR, Kesavapany S (2012) Cdk5/p25-induced cytosolic PLA2-mediated lysophosphatidylcholine production regulates neuroinflammation and triggers neurodegeneration. J Neurosci 32, 1020-1034.

[54] Kuczynski B, Reo NV (2006) Evidence that plasmalogen is protective against oxidative stress in the rat brain. Neurochem Res 31, 639-656.

[55] Farooqui AA, Rapoport SI, Horrocks LA (1997) Membrane phospholipid alterations in Alzheimer's disease: Deficiency of ethanolamine plasmalogens. Neurochem Res 22, 523-527.

[56] Hauff KD, Hatch GM (2006) Cardiolipin metabolism and Barth Syndrome. Prog Lipid Res 45, 91-101.

[57] Chu CT, Ji J, Dagda RK, Jiang JF, Tyurina YY, Kapralov AA, Tyurin VA, Yanamala N, Shrivastava IH, Mohammadyani D, Qiang Wang KZ, Zhu J, Klein-Seetharaman J, Balasubramanian K, Amoscato AA, Borisenko G, Huang Z, Gusdon AM, Cheikhi A, Steer EK, Wang R, Baty C, Watkins S, Bahar I, Bayir H, Kagan VE (2013) Cardiolipin externalization to the outer mitochondrial membrane acts as an elimination signal for mitophagy in neuronal cells. Nat Cell Biol 15, 1197-1205.

[58] Schlame M, Towbin JA, Heerdt PM, Jehle R, DiMauro S, Blanck TJ (2002) Deficiency of tetralinoleoyl-cardiolipin in Barth syndrome. Ann Neurol 51, 634-637.

[59] Acehan D, Vaz F, Houtkooper RH, James J, Moore V, Tokunaga C, Kulik W, Wansapura J, Toth MJ, Strauss A, Khuchua Z (2011) Cardiac and skeletal muscle defects in a mouse model of human Barth syndrome. J Biol Chem 286, 899-908.

[60] Paradies G, Petrosillo G, Ruggiero FM (1997) Cardiolipindependent decrease of cytochrome c oxidase activity in heart mitochondria from hypothyroid rats. Biochim Biophys Acta 1319, 5-8. 